Article

\title{
Estimating Soil Water Content and Evapotranspiration of Winter Wheat under Deficit Irrigation Based on SWAP Model
}

\author{
Xiaowen Wang ${ }^{1,2,3}$, Huanjie Cai ${ }^{1,2,3, *}$, Liang $\mathrm{Li}^{1,2,3}$ and Xiaoyun Wang ${ }^{1,2,3}$ \\ 1 Key Laboratory of Agricultural Soil and Water Engineering in Arid and Semiarid Areas, \\ Ministry of Education, Northwest A\&F University, Yangling 712100, China; \\ wangxiaowen@nwafu.edu.cn (X.W.); liliangzero@nwafu.edu.cn (L.L.); 775638278@nwafu.edu.cn (X.W.) \\ 2 Institute of Water-saving Agriculture in Arid Areas of China, Northwest A\&F University, \\ Yangling 712100, China \\ 3 College of Water Resources and Architectural Engineering, Northwest A\&F University, \\ Yangling 712100, China \\ * Correspondence: huanjiec@yahoo.com
}

Received: 27 September 2020; Accepted: 7 November 2020; Published: 13 November 2020

check for updates

\begin{abstract}
Deficit irrigation strategy is essential for sustainable agricultural development in arid regions. A two-year deficit irrigation field experiment was conducted to study the water dynamics of winter wheat under deficit irrigation in Guanzhong Plain in Northwest China. Three irrigation levels were implemented during four growth stages of winter wheat: $100 \%, 80 \%$ and $60 \%$ of actual evapotranspiration (ET) measured by the lysimeter with sufficient irrigation treatment (CK). The agro-hydrological model soil-water-atmosphere-plant (SWAP) was used to simulate the components of the farmland water budget. Sensitivity analysis for parameters of SWAP indicated that the saturated water content and water content shape factor $n$ were more sensitive than the other parameters. The verification results showed that the SWAP model accurately simulated soil water content (average relative error (MRE) $<21.66 \%$, root mean square error (RMSE) $<0.07 \mathrm{~cm}^{3} \mathrm{~cm}^{-3}$ ) and ET $\left(R^{2}=0.975, p<0.01\right)$. Irrigation had an important impact on actual plant transpiration, but the actual soil evaporation had little change among different treatments. The average deep percolation was $14.54 \mathrm{~mm}$ and positively correlated with the total irrigation amount. The model established using path analysis and regression methods for estimating ET performed well $\left(R^{2}=0.727, p<0.01\right)$. This study provided effective guidance for SWAP model parameter calibration and a convenient way to accurately estimate ET with fewer variables.
\end{abstract}

Keywords: irrigation pattern; crop model; evapotranspiration; sensitivity analysis; path analysis

\section{Introduction}

The Guanzhong Plain is rich in fertile land and abundant in light and heat resources. The plain is an important winter wheat (Triticum aestivum L.) producing area in Northwest China [1]. The total planting area and yield of winter wheat accounts for $80 \%$ and $85 \%$ of Shaanxi Province, respectively [2]. Winter wheat production has great significance for ensuring food security, social stability and agricultural economic development [3]. Restricted water for irrigation is an important factor limiting the growth and production of winter wheat $[1,4-6]$. In recent years, the rapid development of urbanization and industrialization has caused serious water pollution and a reduction of freshwater resources for irrigation [7-9]. Due to climate change and the uneven spatial and temporal distribution of water resources in the region, the drought risk in Northwest China has increased [10]. In addition, unrestrained planting and irrigation have caused a serious waste of water resources. In moderate 
drought years, the water shortage is $25.8 \%$ [11], making winter wheat susceptible to water stress. The potential fragility of agricultural production is increasing, and threatens the sustainable development of agriculture in the region and throughout China [12,13].

Therefore, it is essential to develop a scientific and rational adjustment of the irrigation system for distributing limited irrigation water during the critical period of winter wheat demand. Deficit irrigation is an irrigation strategy that applies less water than the crop water requirements during the growing season to minimize the irrigation amount [6] and maximize water use efficiency [14-17]. To investigate the impact of different degrees of water stress on crops, some researchers have summarized the mechanisms of crop compensation effects and clarified the physiological and biochemical theoretical basis for improving the overall drought resistance [18,19]. Zheng et al. [1] and Tari [20] concluded that mild water stress during the seeding and tillering stage, and sufficient water irrigation during the jointing stage resulted in a high grain yield. Deficit irrigation not only affects crop growth but also changes water use in the soil plant atmosphere continuum (SPAC) [21]. Based on the data from the evapotranspiration (ET) network, Schneider and Howell [22] analyzed the water balance and yield composition of wheat field and determined the water use efficiency under deficit irrigation. The research results of Jiang et al. [8] indicated that the daily ET difference between sufficient irrigation and deficit irrigation was obvious. This difference began to appear from jointing and became more pronounced during the heading and grouting stages. Wang et al. [23] conducted a deficit irrigation study on winter wheat, and the results showed that the deficit irrigation had great impacts on plant transpiration, but not on soil evaporation. As one of the largest components of the water cycle, accurately measuring and modeling ET is critical for improving and optimizing agricultural water management [24,25]. However, the specific effects of weather, crop, and soil factors on ET are still seldom studied. The internal relationship between these factors and their direct and indirect effects on ET need to be further investigated. In particular, it is not clear how water stress limits the actual ET under deficit irrigation. On the basis of clarifying the above influences, accurate estimation of actual ET under deficit irrigation is also particularly important for field water management.

Many researchers have applied agricultural numerical models to simulate the impact of deficit irrigation on crop growth [26], water use efficiency and the dynamics of water balance [27]. The agro-hydrological model soil-water-atmosphere-plant (SWAP) can simulate the interactions of water, solutes, heat and crop growth using meteorological, crop and soil data [28]. Eitzinger et al. [29] and Bonfante et al. [30] compared the performance of SWAP to other crop models and pointed out that SWAP simulated soil infiltration and drying processes more accurately. Furthermore, the SWAP model simulated the field water balance and irrigation practices reasonably well [31]. Crop models simulate highly complex agricultural phenomena through the numerical process. The performance of the model is closely related to the quality of the input parameters. Therefore, obtaining accurate parameters through observation or estimation is very important for improving simulation accuracy. However, crop models often require a large number of parameters, so it is often unrealistic to estimate each parameter. Sensitivity analysis helps to identify parameters to which the model outputs are sensitive and determine the optimal parameter adjustment strategy. This helps model users to complete parameter estimation and model localization more efficiently [32,33]. Different from other crop models, such as DSSAT (decision support system for agrotechnology transfer), GMS (groundwater modeling system), and RZWQM2 (root zone water quality model) [34], the SWAP model has no nested parameter sensitivity analysis and estimation module. This makes the calibration of the SWAP model very complicated, which greatly limits the application of the model.

Based on a two-year deficit irrigation experiment of winter wheat in Guanzhong Plain, this paper used the SWAP model to study the effects of water stress conditions on the farmland water system. The objectives of this study were as follows: (1) based on the results of sensitivity analysis, the SWAP model is calibrated and verified to evaluate the local applicability; (2) to analyze the pattern of farmland water transformation under deficit irrigation; and (3) based on path analysis, identify the main influencing factors of ET and construct an estimation model of actual ET under deficit irrigation. 


\section{Materials and Methods}

\subsection{Experimental Area}

The experiment was carried out from October 2012 to June 2014 at the Institute of Water-saving Agriculture in Arid Areas of China $\left(108^{\circ} 04^{\prime} \mathrm{E}, 34^{\circ} 17^{\prime} \mathrm{N}, 521 \mathrm{~m}\right.$ above sea level), Northwest A\&F University, Yangling, Shaanxi Province, China. The area has a continental temperate monsoon climate, and the multi-year average temperature and precipitation are $12.5{ }^{\circ} \mathrm{C}$ and $609 \mathrm{~mm}$, respectively. The average temperature and precipitation of the two growing seasons are $8.42{ }^{\circ} \mathrm{C}, 220.10 \mathrm{~mm}$ (2012-2013 growing season) and $8.35^{\circ} \mathrm{C}, 290.30 \mathrm{~mm}$ (2013-2014 growing season), as shown in Figure 1. The local soil texture is silty clay loam [21]. The average field water capacity of the $1 \mathrm{~m}$ soil layer is $0.32 \mathrm{~cm}^{3} \mathrm{~cm}^{-3}$, and the average bulk density of the soil was $1.39 \mathrm{~g} \mathrm{~cm}^{-3}$ (Table 1). The groundwater is below $50 \mathrm{~m}$, and groundwater recharge can be ignored. The area of each plot is $6.6 \mathrm{~m}^{2}$ (length: $3 \mathrm{~m}$, width: $2.2 \mathrm{~m}$ ). A concrete side wall was utilized to prevent water side seepage. The bottom of the plot was provided with a filter layer for free drainage. A mobile electric shelter was installed above the test area, which was closed (manually) during precipitation and opened when precipitation did not occur (Figure 2).

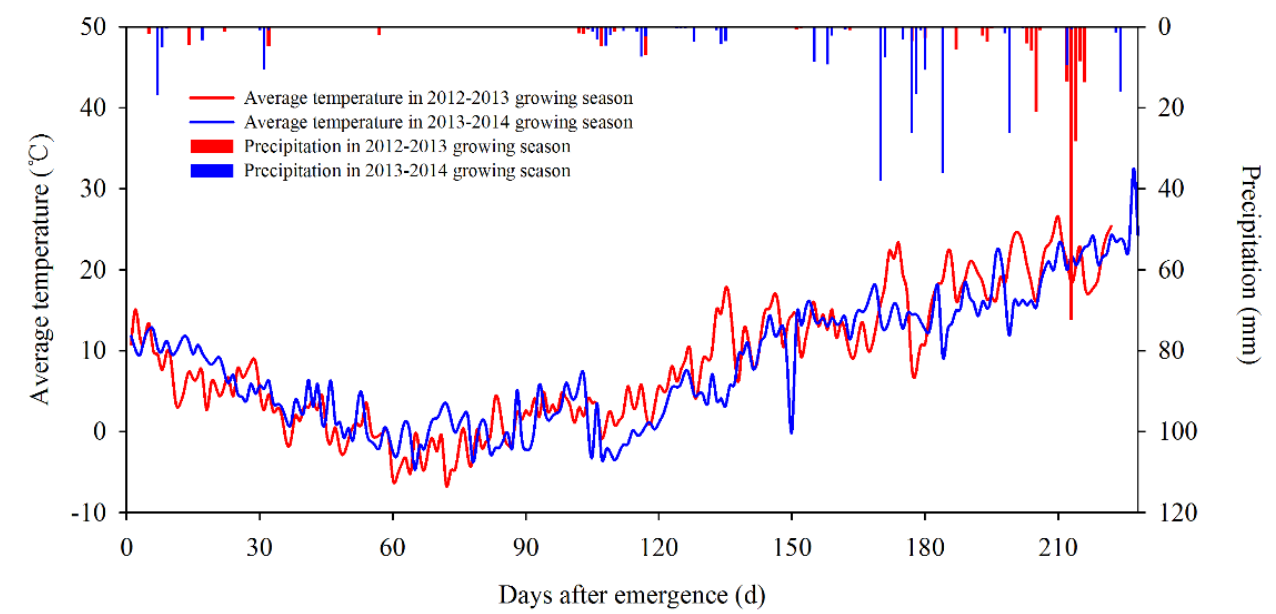

Figure 1. The daily average temperature and precipitation during the 2012-2014 winter wheat growing season.

Table 1. Physical properties of the soil at the experimental area in Yangling, Shaanxi Province, China.

\begin{tabular}{|c|c|c|c|c|c|}
\hline \multirow{2}{*}{ Soil Physical Properties } & \multicolumn{5}{|c|}{ Soil Layers (cm) } \\
\hline & $0-20$ & $20-40$ & $40-60$ & $60-80$ & 80-100 \\
\hline Sand $(\%)$ & 26.71 & 24.98 & 22.11 & 22.11 & 22.11 \\
\hline Silt $(\%)$ & 50.85 & 52.78 & 54.75 & 54.75 & 54.75 \\
\hline Clay $(\%)$ & 22.10 & 22.10 & 20.90 & 20.90 & 20.90 \\
\hline Bulk density $\left(\mathrm{g} \mathrm{cm}^{-3}\right)$ & 1.32 & 1.40 & 1.41 & 1.41 & 1.41 \\
\hline $\begin{array}{l}\text { Field water capacity (volume water content, } \\
\left.\qquad \mathrm{cm}^{3} \mathrm{~cm}^{-3}\right)\end{array}$ & 0.34 & 0.32 & 0.31 & 0.36 & 0.36 \\
\hline
\end{tabular}




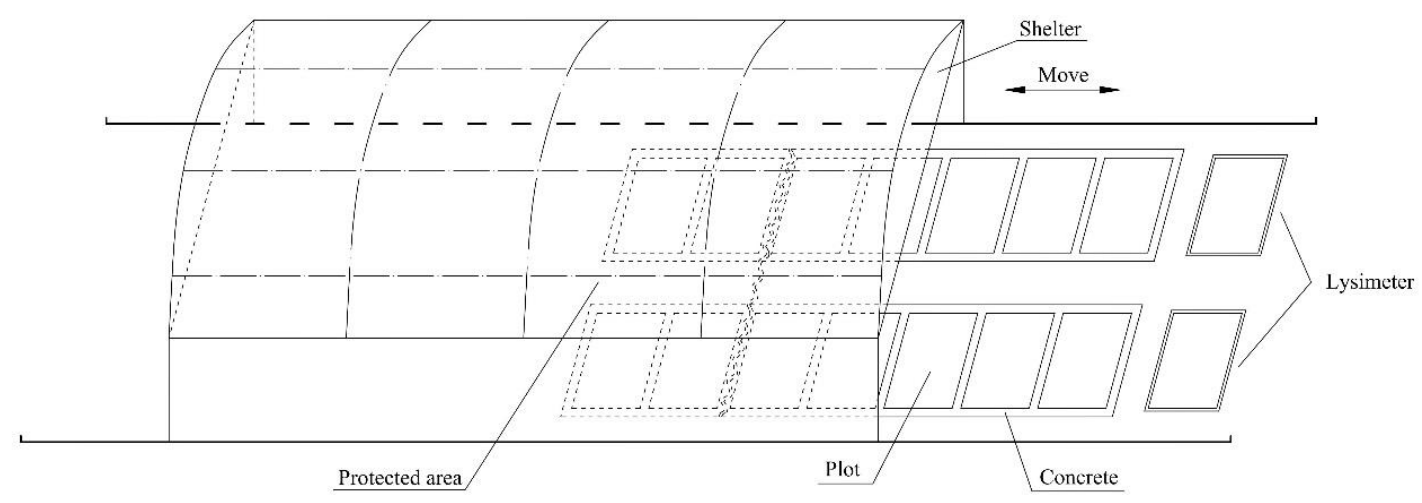

Figure 2. Diagram of the location of the test plots and shelter at the experimental site.

\subsection{Experimental Design}

The winter wheat variety was "Xiaoyan 22 " and the planting density was 357 seeds $\mathrm{m}^{-2}$. The sowing times of the two-year experiment were 18 October 2012 and October 15, 2013. The harvest times were 3 June 2013 and 8 June 2014. Each treatment received N $244 \mathrm{~kg} \mathrm{ha}^{-1}$ and $\mathrm{P}_{2} \mathrm{O}_{5} 270 \mathrm{~kg} \mathrm{ha}^{-1}$ at the sowing stage. The irrigation method was surface irrigation. The entire growth period of the winter wheat was divided into four stages: emergence-jointing stage, jointing-heading stage, heading-grouting stage and grouting-mature stage. Three irrigation levels were implemented during each stage: $100 \%$ (no water deficit), $80 \%$ (moderate deficit) and $60 \%$ (severe deficit) of actual ET measured by the large weighing lysimeter with sufficient irrigation treatment (CK, namely W1 and T1) (Figure 3). The range of the device was 0 to $6 \mathrm{t}$, and the measurement accuracy was less than $150 \mathrm{~g}$ [35]. The size of the lysimeter is consistent with the plot. A 4-factor 3-level partial orthogonal test design was used with nine treatments that were replicated three times (Table 2).

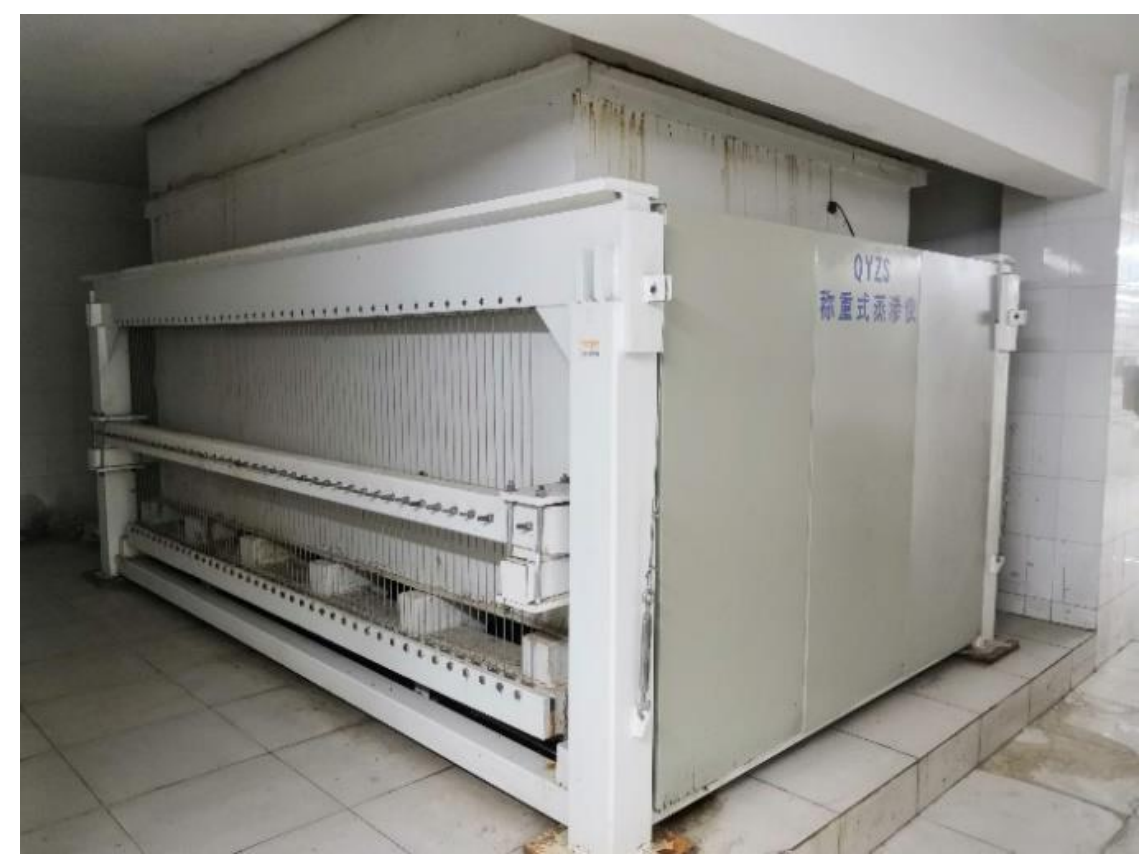

Figure 3. Large weighing lysimeter arranged in no water deficit treatment plot (W1 and T1). 
Table 2. Nine irrigation treatments based on actual evapotranspiration under sufficient irrigation (W1 and T1) measured by the lysimeter at four growth stages of winter wheat during the 2012-2013 and 2013-2014 growing seasons.

\begin{tabular}{|c|c|c|c|c|c|}
\hline \multirow{2}{*}{ Year } & \multirow{2}{*}{ Treatments } & \multicolumn{4}{|c|}{ Irrigation (\%ET) } \\
\hline & & Emergence-Jointing & Jointing-Heading & Heading-Grouting & Grouting-Maturity \\
\hline \multirow{9}{*}{ 2012-2013 } & W1 (CK) & 100 & 100 & 100 & 100 \\
\hline & W2 & 100 & 80 & 80 & 80 \\
\hline & W3 & 100 & 60 & 60 & 60 \\
\hline & W4 & 80 & 100 & 80 & 60 \\
\hline & W5 & 80 & 80 & 60 & 100 \\
\hline & W6 & 80 & 60 & 100 & 80 \\
\hline & W7 & 60 & 100 & 60 & 80 \\
\hline & W8 & 60 & 80 & 100 & 60 \\
\hline & W9 & 60 & 60 & 80 & 100 \\
\hline \multirow{9}{*}{ 2013-2014 } & $\mathrm{T} 1(\mathrm{CK})$ & 100 & 100 & 100 & 0 \\
\hline & $\mathrm{T} 2$ & 100 & 80 & 80 & 0 \\
\hline & $\mathrm{T} 3$ & 100 & 60 & 60 & 0 \\
\hline & $\mathrm{T} 4$ & 80 & 100 & 60 & 0 \\
\hline & $\mathrm{T} 5$ & 80 & 80 & 100 & 0 \\
\hline & $\mathrm{T} 6$ & 80 & 60 & 80 & 0 \\
\hline & $\mathrm{T} 7$ & 60 & 100 & 80 & 0 \\
\hline & $\mathrm{T} 8$ & 60 & 80 & 60 & 0 \\
\hline & T9 & 60 & 60 & 100 & 0 \\
\hline
\end{tabular}

Note: Three irrigation levels were set at each stage: no deficit (100\% ET), moderate deficit ( $80 \%$ ET) and severe deficit (60\% ET); Irrigation dates of 2012-2013: 2012.12.27, 2013.3.15, 2013.4.11, 2013.5.4; Irrigation dates of 2013-2014: 2013.12.28, 2014.3.31, 2014.5.8; the dates of each growth stage in the 2012-2013 growing season are 2012.10.25-2013.3.14, 2013.3.15-2013.4.9, 2013.4.10-2013.5.1, 2013.5.2-2013.6.3; the dates of each growth stage in the 2013-2014 growing season are 2013.10.24-2014.3.25, 2014.3.26-2014.4.19, 2014.4.20-2014.5.15, 2014.5.16-2014.6.8.

\subsection{Observation Indicators}

\section{Meteorological data}

Daily weather data were obtained from the national general weather station near the plots (The distance between them is approximately $0.3 \mathrm{~km}$ ), including maximum temperature $\left(\mathrm{T}_{\max },{ }^{\circ} \mathrm{C}\right)$, minimum temperature $\left(\mathrm{T}_{\min },{ }^{\circ} \mathrm{C}\right)$, average relative humidity $(\mathrm{RH}, \%)$, wind speed $\left(\mathrm{u}_{10}, \mathrm{~m} \mathrm{~s}^{-1}\right.$, the wind speed sensor was $10.2 \mathrm{~m}$ above the ground), sunshine duration $\left(\mathrm{S}_{\mathrm{d}}, \mathrm{h}\right)$ and precipitation $(\mathrm{P}, \mathrm{mm})$.

2. Soil data

Soil profile data was obtained from field measurements. The detailed physical properties of each soil layer are shown in Table 1 . The soil water content (SWC) of the $1 \mathrm{~m}$ soil layer was measured by the method of weighing after drying. Every $10 \mathrm{~cm}$ soil depth was a measurement point, and the specific sampling time is shown in Figure 4.

\section{Crop ET}

The crop ET of each treatment was calculated using the water balance method:

$$
\begin{gathered}
E T=I-D-\Delta W \\
\Delta W=1000 \times Z_{r}\left[\theta\left(t_{2}\right)-\theta\left(t_{1}\right)\right]
\end{gathered}
$$

where $I$ is irrigation $(\mathrm{mm}) ; D$ is deep percolation $(\mathrm{mm}) ; \Delta W$ is the change of soil water storage in the root zone $(\mathrm{mm}) ; Z_{r}$ is root zone depth $(\mathrm{m}) ; \theta\left(t_{1}\right)$ and $\theta\left(t_{2}\right)$ are the average soil volume water content of the root zone at $t_{1}$ and $t_{2}$ respectively. 
- Sampling time for soil water content

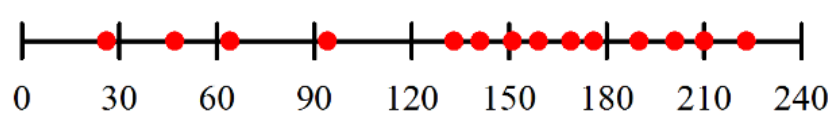

Days after emergence (d)

(a) 2012-2013 growing season

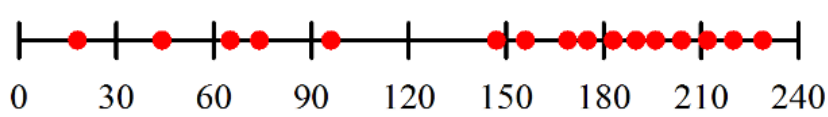

Days after emergence (d)

(b) 2013-2014 growing season

Figure 4. Sampling time of soil water content in the 2012-2013 and 2013-2014 growing seasons.

\section{Crop height $(\mathrm{CH})$}

Ten wheat plants were selected in each plot, and $\mathrm{CH}$ was measured using a tape measure with an accuracy of $1 \mathrm{~mm}$ every week.

5. Leaf area index (LAI)

The SunScan-SS1 canopy analyzer (Delta-T Devices Ltd., Cambridge, UK) was used at each growth stage of winter wheat to measure LAI.

\subsection{SWAP Model Introduction and Sensitivity Analysis}

\subsubsection{Basic Principles}

1. Water flow

The SWAP model uses one-dimensional Richards equations to describe the water flow and has a strong physical foundation $[30,36]$ :

$$
C(h) \frac{\partial h}{\partial t}=\frac{\partial\left[K(h)\left(\frac{\partial h}{\partial z}+1\right)\right]}{\partial z}-S(z)
$$

where $C(h)$ is the differential water capacity $\left(\mathrm{cm}^{-1}\right)$, indicating the change in water content caused by the change of the unit matrix potential, and is numerically equal to the slope of the soil water characteristic; $t$ is time (d); $K$ is the hydraulic conductivity $\left(\mathrm{cm} \mathrm{d}^{-1}\right) ; h$ is the soil water pressure head $(\mathrm{cm}) ; z$ is the vertical coordinate $(\mathrm{cm})$ taken positively upward; and $S(z)$ is the root water uptake at a certain depth $\left(\mathrm{cm}^{3} \mathrm{~cm}^{-3} \mathrm{~d}^{-1}\right)$.

2. Evapotranspiration

SWAP offers two methods for the distribution of plant transpiration and soil evaporation. One is based on crop and soil factors and the other is a direct application of the Penman-Monteith equation. The direct application of the Penman-Monteith equation was used in this study. This method does not require crop or soil factors to translate reference ET to crop ET and avoids the complicated calibration 
process [28]. The functions of potential plant transpiration $\left(T_{p}\right)$ and soil evaporation $\left(E_{p}\right)$ are as follows [21,28]:

$$
\begin{gathered}
T_{p}=\frac{\left(1-W_{f r a c}\right)\left(V_{c} \frac{\Delta_{v}}{\lambda_{w}}\left(R_{n}-G\right)+\frac{p_{1} \rho_{a} C_{a}}{\lambda_{w}}\left(\frac{e_{s}-e_{a}}{r_{a}^{c}}\right)\right)}{\Delta_{v}+\gamma\left(1+\frac{r_{c, \text { min }}}{r_{a}^{c}}\right)} \\
E_{p}=\frac{\left(1-V_{c}\right) \frac{\Delta_{v}}{\lambda_{w}}\left(R_{n}-G\right)+\frac{p_{1} \rho_{a} C_{a}}{\lambda_{w}}\left(\frac{e_{s}-e_{a}}{r_{a}^{s}}\right)}{\Delta_{v}+\gamma\left(1+\frac{r_{s, \min }}{r_{a}^{s}}\right)}
\end{gathered}
$$

where $W_{f r a c}$ is the fraction of a day that the canopy is wet (-), since the shelter was closed during precipitation events, the rainfall interception was not considered in this study, and $W_{\text {frac }}$ was set to 0 [28]; $V_{c}$ is the vegetation cover (-) (function 6); $\Delta_{v}$ is the slope of the water vapor pressure curve $\left(\mathrm{kPa}^{\circ} \mathrm{C}^{-1}\right) ; \lambda_{w}$ is the latent heat of evaporation $\left(\mathrm{J} \mathrm{kg}^{-1}\right) ; R_{n}$ is the net radiant flux at the canopy surface $\left(\mathrm{J} \mathrm{m}^{-2} \mathrm{~d}^{-1}\right) ; G$ is the heat flux of the soil $\left(\mathrm{J} \mathrm{m}^{-2} \mathrm{~d}^{-1}\right)$, which is negligible on a daily basis; $p_{1}$ is the unit conversion factor, $86400\left(\mathrm{~s} \mathrm{~d}^{-1}\right) ; \rho_{a}$ is the air density $\left(\mathrm{kg} \mathrm{m}^{-3}\right) ; C_{a}$ is heat capacity of moist air $\left(\mathrm{J} \mathrm{kg}^{-1}{ }^{\circ} \mathrm{C}^{-1}\right) ; e_{s}$ is the saturation vapor pressure $(\mathrm{kPa}) ; e_{a}$ is the actual vapor pressure $(\mathrm{kPa}) ; r_{a}{ }^{c}$ is the aerodynamic resistance of the canopy surface corrected according to $V_{c} ; \gamma$ is the wet and dry thermometer constant $\left(\mathrm{kPa}^{\circ} \mathrm{C}^{-1}\right) ; r_{c, \text { min }}$ is the minimum canopy resistance $\left(\mathrm{s} \mathrm{m}^{-1}\right)$, with a value of 20 selected according to Feng et al. [37]; $r_{a}{ }^{s}$ is the aerodynamic resistance of the soil surface corrected according to $V_{c} ; r_{s, \min }$ is the minimum soil resistance, i.e., the wet soil resistance $\left(\mathrm{s} \mathrm{m}^{-1}\right)$, and a value of zero was selected according to the model value range.

$$
V_{c}=1-e^{-k_{d i r} k_{d i f} L A I}
$$

where $k_{d i r}$ and $k_{d i f}$ are the direct and diffuse optical extinction coefficients (-), respectively, taking the model default values of 0.60 and 0.75 [38].

The potential root water uptake $\left(S_{p}\right)$ is equal to $T_{p}[28]$, and the actual root water uptake $\left(S_{a}\right)$ should consider the effects of water, salt and low temperature stress:

$$
S_{a}(z)=\alpha_{r w} \alpha_{r d} \alpha_{r s} \alpha_{r f} S_{p}(z)
$$

where $\alpha_{r w}, \alpha_{r d}, \alpha_{r s}$, and $\alpha_{r f}(-)$ are the wet, dry, salt and low temperature stress coefficients, respectively. This test used local groundwater for surface irrigation, regardless of salt and low temperature stress. The water stress in SWAP is a piecewise linear function proposed by Feddes et al. 1978 [39]. The parameters of the water stress function are based on previous research $[37,40,41]$.

The actual plant transpiration $\left(T_{a}\right)$ is obtained by integrating $S_{a}$. The actual soil evaporation $\left(\mathrm{E}_{\mathrm{a}}\right)$ is the smaller value between $E_{p}$ and maximum soil evaporation $[28,29]$ :

$$
\begin{gathered}
T_{a}=\int_{-Z_{r}}^{0} S_{a}(z) \partial z \\
E_{\max }=K_{1 / 2}\left(\frac{h_{a t m}-h_{1}-z_{1}}{z_{1}}\right)
\end{gathered}
$$

where $E_{\max }$ is maximum soil evaporation $\left(\mathrm{cm} \mathrm{d}^{-1}\right) ; K_{1 / 2}$ is the average hydraulic conductivity $\left(\mathrm{cm} \mathrm{d}^{-1}\right)$ between the soil surface and the first node; $h_{\text {atm }}$ is the soil water pressure $(\mathrm{cm})$ balanced with the relative humidity of the atmosphere; $h_{1}$ is the first soil water pressure $(\mathrm{cm})$ of the node; and $z_{1}$ is the soil depth $(\mathrm{cm})$ of the first node. 


\subsubsection{Model Input}

The data required by the meteorological module were obtained from the weather station near the test area. The soil module was needed to discretize the vertical soil profile. In our study, the $1 \mathrm{~m}$ soil depth was divided into five layers. Based on the recommended value of the model and previous research, each soil layer was further divided into compartments of different thicknesses [28]. The crop module needed to input the growth stage to establish a function of LAI, $\mathrm{CH}$ and root length with the development stage (DVS). Due to the lack of root length data, the longest root length of winter wheat was set to $1 \mathrm{~m}$ following Jha et al. [42]. The root length of all other stages was obtained based on interpolation using $\mathrm{CH}$ [37]. There are two types of simulations for the crop growth process: a simple module and a detailed module [28]. This paper focuses on field water movement and therefore selects the simple crop module. The upper boundary of the simulation was located above the crop canopy, and the lower boundary was set to $1 \mathrm{~m}$ below the soil surface. The bottom drained freely, and lateral percolation and groundwater recharge were not considered. Other model theory and calculation methods can refer to Kroes et al. [28].

\subsubsection{Sensitivity Analysis}

Sensitivity analysis is a prerequisite for model calibration [33]. The calibration of the simple module in the SWAP model is the process of continuously adjusting the van Genuchten-Mualem model (VGM) parameters to minimize the deviation between the simulation SWC and the observed values $[31,35,37]$. Therefore, we mainly analyzed the sensitivity of VGM parameters. This study used the parameter change method for sensitivity analysis [43,44]. The sensitivity index (SI) was used to evaluate the influence of parameters on the model results $[45,46]$. The specific steps were as follows:

3. Determine the initial value of the VGM parameters

The measured soil physical properties (Table 1) were fitted to the VGM equations with the RETC software [47]. The fitted values were considered as the initial soil parameters in model calibration [31,48].

4. Determine the change range

The range of local VGM parameters was measured or simulated according to previous studies $[49,50]$. Based on the initial values obtained by the first step above and the local range, changes of $\pm 10 \%, \pm 20 \%, \pm 30 \%$, and $\pm 50 \%$ were set as model inputs.

5. Calculate the SI

The SI was calculated by the following function $[43,46]$ :

$$
S I=\frac{Y_{i}-Y_{0}}{Y_{0}}
$$

where $Y_{0}$ is the model output (SWC or ET in this study) under the condition that the parameters are the initial value and $Y_{i}$ represents the output after changing the parameters.

6. Sensitivity ranking consistency test

The consistency of the sensitivity ranking was evaluated by the TDCC coefficient (top-down coefficient of concordance) $[32,51,52]$. The specific calculation process was as follows: 
First, the absolute values of the SI were sorted to get the following matrix:

$$
\begin{array}{ccccc} 
& R_{1} & R_{2} & \cdots & R_{m} \\
x_{1} & r\left(O_{11}\right) & r\left(O_{12}\right) & \cdots & r\left(O_{1 m}\right) \\
x_{2} & r\left(O_{21}\right) & r\left(O_{22}\right) & \cdots & r\left(O_{21}\right) \\
\vdots & \vdots & \vdots & \cdots & \vdots \\
x_{n} & r\left(O_{n 1}\right) & r\left(O_{n 2}\right) & \cdots & r\left(O_{n m}\right)
\end{array}
$$

where $O_{i j}$ is the outcome (i.e., the absolute $S I$ value) for the $i_{\text {th }}$ parameter in the $j_{t h}$ sensitivity analysis test; $r\left(O_{i j}\right)$ is the order of the $i_{\text {th }}$ parameter in the $j_{\text {th }}$ sensitivity analysis test (the absolute SI value ranges from high to low);

Then, the Savage score matrix was calculated [53], and the following matrix was obtained:

$$
s s\left(O_{i j}\right)=\sum_{i=r\left(O_{i j}\right)}^{n} 1 / i
$$

where $s s\left(O_{i j}\right)$ is the Savage score of the $i_{t h}$ parameter in the $j_{t h}$ sensitivity analysis test; and $n$ is the number of model parameters (the value is 5 in this study, which represents the five soil VGM parameters: $\theta_{\mathrm{r}}, \theta_{\mathrm{s}}, \mathrm{K}_{\mathrm{s}}, \alpha$ and $\mathrm{n}$ ).

$$
\begin{array}{ccclc} 
& R_{1} & R_{2} & \cdots & R_{m} \\
x_{1} & s s\left(O_{11}\right) & s s\left(O_{12}\right) & \cdots & s s\left(O_{1 m}\right) \\
x_{2} & s s\left(O_{21}\right) & s s\left(O_{22}\right) & \cdots & s s\left(O_{21}\right) \\
\vdots & \vdots & \vdots & \cdots & \vdots \\
x_{n} & s s\left(O_{n 1}\right) & s s\left(O_{n 2}\right) & \cdots & s s\left(O_{n m}\right)
\end{array}
$$

Finally, the TDCC coefficient is:

$$
T D C C=\frac{\sum_{i=1}^{n}\left(\sum_{j=1}^{m} s s\left(O_{\mathrm{ij}}\right)\right)^{2}-m^{2} n}{m^{2}\left(n-\sum_{i=1}^{n} 1 / i\right)}
$$

where $m$ is the number of sensitivity analysis tests (the value is 8 in this study, which represents eight different changes of $\pm 10 \%, \pm 20 \%, \pm 30 \%$, and $\pm 50 \%$ ).

The significant $\mathrm{P}$ value of the TDCC coefficient is calculated by the statistic T:

$$
T=m(n-1) T D C C
$$

where the statistic $T$ in the function approximates the $\chi^{2}$ distribution with a degree of freedom of $n-1$. Generally, the $p$ value is less than 0.05 at a larger TDCC value. This means that the parameter sensitivity ranking of each sensitivity analysis test has significant consistency $[32,52,54]$.

\subsubsection{Model Calibration and Verification}

Based on the sensitivity analysis results, we adopt different parameter adjustment strategies to calibrate the SWAP model. This study selected the W4, W5 and T4, T5 treatments for model calibration because their irrigation amounts were at a medium level compared with the other treatments. We avoided using extreme treatments (irrigated too much or too little) for model calibration to ensure that the calibration results also apply to general irrigation. The degree of agreement between the simulated and measured SWC was evaluated by the average relative error (MRE) and the root mean square error (RMSE):

$$
M R E=\frac{\sum_{i=1}^{n}\left|\frac{P_{i}-O_{i}}{O_{i}}\right|}{n} \times 100 \%
$$




$$
\text { RMSE }=\sqrt{\frac{\sum_{i=1}^{n}\left(P_{i}-O_{i}\right)^{2}}{n}}
$$

where $n$ is the number of measured values; $P_{i}$ is the $i_{\text {th }}$ predicted value; and $O_{\mathrm{i}}$ is the $i_{\text {th }}$ observed value.

We adjusted the corresponding VGM parameters in SWAP until MRE $\leq 20 \%$ and RMSE $\leq 0.05 \mathrm{~cm}^{3}$ $\mathrm{cm}^{-3}[30,35,37,55]$. The adjusted parameters were used for model verification for all other treatments. The calibrated VGM parameters are shown in Table 3.

Table 3. The initial and calibration values of the van Genuchten-Mualem model (VGM) parameters in the SWAP model.

\begin{tabular}{|c|c|c|c|c|c|c|c|c|c|c|}
\hline \multirow{4}{*}{$\begin{array}{l}\text { Soil } \\
\text { Layers } \\
\text { (cm) }\end{array}$} & \multirow{2}{*}{\multicolumn{2}{|c|}{$\begin{array}{l}\text { Residual Water Content } \theta_{\mathrm{r}} \\
\qquad\left(\mathrm{cm}^{3} \mathrm{~cm}^{-3}\right)\end{array}$}} & \multirow{2}{*}{\multicolumn{2}{|c|}{$\begin{array}{l}\text { Saturated Water } \\
\text { Content } \theta_{\mathrm{s}} \\
\left(\mathrm{cm}^{3} \mathrm{~cm}^{-3}\right)\end{array}$}} & \multirow{2}{*}{\multicolumn{2}{|c|}{$\begin{array}{l}\text { Saturated Hydraulic } \\
\text { Conductivity } K_{s} \\
\left(\mathrm{~cm} \mathrm{~d}^{-1}\right)\end{array}$}} & \multicolumn{4}{|c|}{ Water Content Shape Factor } \\
\hline & & & & & & & \multicolumn{2}{|c|}{$\alpha\left(\mathrm{cm}^{-1}\right)$} & \multicolumn{2}{|c|}{$\mathrm{n}$} \\
\hline & Initial & Calibration & Initial & Calibration & n Initial & Calibra & nInitial & Calibration & Initial & Calibration \\
\hline & Values & Values & Values & Values & Values & Values & Values & Values & Values & Values \\
\hline $0-20$ & 0.07 & 0.10 & 0.43 & 0.42 & 19.37 & 15.00 & 0.01 & 0.040 & 1.61 & 1.30 \\
\hline $20-40$ & 0.07 & 0.13 & 0.41 & 0.41 & 13.12 & 15.00 & 0.01 & 0.030 & 1.61 & 1.70 \\
\hline $40-60$ & 0.07 & 0.10 & 0.41 & 0.49 & 13.56 & 10.00 & 0.01 & 0.035 & 1.62 & 1.70 \\
\hline $60-80$ & 0.07 & 0.10 & 0.41 & 0.47 & 13.56 & 10.00 & 0.01 & 0.040 & 1.62 & 1.70 \\
\hline $80-100$ & 0.07 & 0.10 & 0.41 & 0.45 & 13.56 & 7.00 & 0.01 & 0.045 & 1.62 & 1.55 \\
\hline
\end{tabular}

\subsection{Path Analysis and Establishment of the ET Estimation Model}

Path analysis is a multivariate statistical analysis technique that studies the relationship between independent variables and dependent variables [56]. The reliability of this method has been verified in many studies [57-60]. This method can help to analyze the direct and indirect effects of the independent variable on the dependent variable, and get the decision coefficient (DC) of each factor:

$$
D C(i)=2 p_{i} r_{i y}-p_{i}^{2}
$$

where $D C(i)$ is the decision coefficient of the independent variable, $i ; p_{i}$ is the direct path coefficient of the independent variable, $i$; and $r_{i y}$ is the correlation coefficient between the independent variable $i$ and the dependent variable $y . D C(i)>0$ indicates that the independent variable promotes the dependent variable, and $D C(i)<0$ indicates that the independent variable has an inhibitory effect on the dependent variable.

Based on ET simulated by the SWAP model, correlation analysis and path analysis were carried out with meteorological factors (radiation, wind speed at $2 \mathrm{~m}, \mathrm{RH}$ and average temperature), crop factors ( $\mathrm{CH}$ and LAI) and soil factors (SWC of different layers). We selected the most relevant factors according to the ranking of DC, and established the ET estimation model under deficit irrigation conditions by multiple nonlinear regression method.

\subsection{Data Processing and Statistical Analysis}

Path analysis, significance analysis, and regression model construction were performed using SPSS 21 (IBM, Armonk, NY, USA).

\section{Results}

\subsection{Sensitivity Analysis}

\subsubsection{Overall Parameter Sensitivity}

Taking the $\pm 30 \%$ change of the VGM parameters as an example, the sensitivity of SWC and ET to the parameters was explained. In terms of total sensitivity, SWC was more sensitive to the VGM parameters than ET. The average SI of the VGM parameter for SWC was 0.045 and -0.017 for ET.

When the parameter values were changed by $+30 \%, \theta_{\mathrm{r}}$ and $\theta_{\mathrm{s}}$ of the $0-20 \mathrm{~cm}$ layer were positively correlated with SWC. The SI values of $\theta_{\mathrm{r}}$ and $\theta_{\mathrm{s}}$ were 0.058 and 0.349 , respectively (Figure $5 \mathrm{a}$ ). $\mathrm{K}_{\mathrm{s}}$, 
$\alpha$ and $\mathrm{n}$ were negatively correlated with SWC, and their SI were $-0.025,-0.033$ and -0.262 , respectively. The absolute SI values of $\theta_{\mathrm{s}}$ and $\mathrm{n}$ were much larger than those of $\theta_{\mathrm{r}}, \alpha$ and $\mathrm{K}_{\mathrm{s}}$. For other soil profiles, the correlation between the VGM parameters and SWC was consistent with the $0-20 \mathrm{~cm}$ soil layer (Figure $5 \mathrm{~b}-\mathrm{e}$ ). For the $20-100 \mathrm{~cm}$ soil layer, the average absolute SI value of each parameter was $\theta_{\mathrm{s}}$ $(0.284)>\mathrm{n}(0.203)>\theta_{\mathrm{r}}(0.049)>\mathrm{K}_{\mathrm{s}}(0.028)>\alpha(0.005)$. When the parameter values changed by $-30 \%$, the positive and negative correlation between the VGM parameters and the SWC of the root zone $(0-100 \mathrm{~cm}$ soil layer) was unchanged. The absolute SI values were slightly different from the $+30 \%$ change: $\mathrm{n}(0.633)>\theta_{\mathrm{s}}(0.284)>\theta_{\mathrm{r}}(0.050)>\mathrm{K}_{\mathrm{s}}(0.037)>\alpha(0.015)$. However, the absolute SI values of the first two parameters $\left(\theta_{\mathrm{S}}\right.$ and $\left.\mathrm{n}\right)$ were still much larger than those of three other parameters.
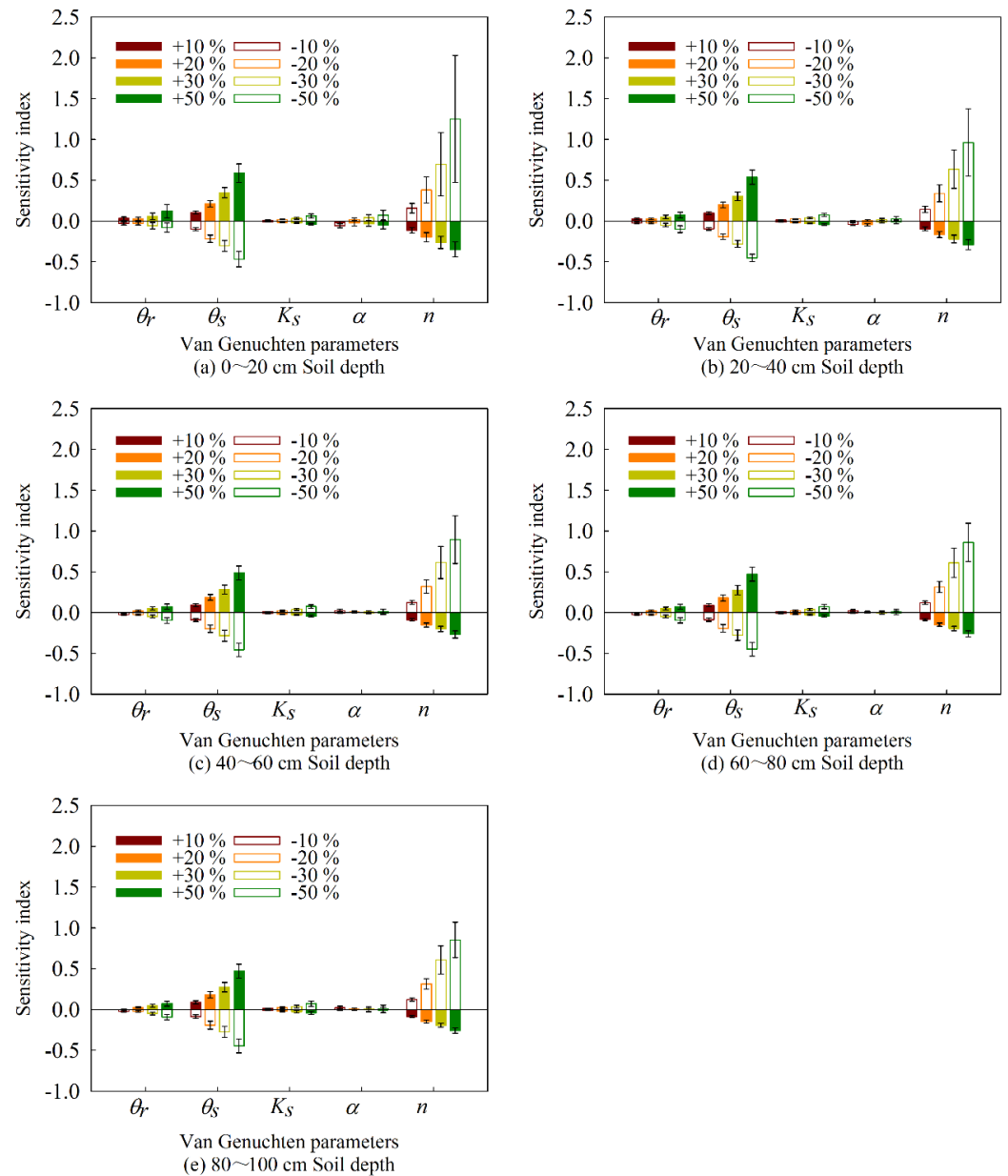

Figure 5. Sensitivity analysis results of the van Genuchten-Mualem model (VGM) parameters for soil profile water content and daily evapotranspiration simulated by SWAP under different parameter change ranges $( \pm 10 \%, \pm 20 \%, \pm 30 \%, \pm 50 \%$ ). (a) 0-20 cm soil layer; (b) 20-40 cm soil layer; (c) $40-60 \mathrm{~cm}$ soil layer; (d) $60-80 \mathrm{~cm}$ soil layer; (e) $80-100 \mathrm{~cm}$ soil layer.

For ET (Figure $6 \mathrm{a}-\mathrm{d}$ ), when the parameter values were changed by $+30 \%$, the average SI values of the emergence-heading stages were negative $\left(\theta_{\mathrm{r}}, \mathrm{K}_{\mathrm{s}}, \alpha\right.$ and $\mathrm{n}$ were $-0.014,-0.006,-0.011$ and -0.061 , respectively) except for $\theta_{\mathrm{s}}(0.084)$. $\theta_{\mathrm{s}}$ and $\alpha$ were positively correlated with ET during the heading-maturity stages, and the other parameters were negatively correlated. The absolute SI values of $\theta_{\mathrm{s}}$ and $\mathrm{n}$ during the heading-grouting stage (0.012 and 0.014$)$ were much lower than in the other growth stages. When the parameter values were changed by $-30 \%, \theta_{\mathrm{s}}$ and $\mathrm{n}$ were positively correlated with ET at the emergence-heading stage. The other parameters were negatively correlated. $\theta_{\mathrm{r}}$ and $\mathrm{K}_{\mathrm{s}}$ were negatively correlated with ET at the heading-maturity stage, and all other parameters were positively correlated with ET. The ranking of the absolute SI values in the emergence-jointing stage was 
consistent with results with the parameter value change of $+30 \%$. The two most sensitive parameters during this growth stage were also $\theta_{\mathrm{S}}(-0.141)$ and $\mathrm{n}(-0.144)$, but the corresponding absolute SI values were generally higher than those observed in response to the change of $+30 \%(0.072$ and -0.080 , respectively).

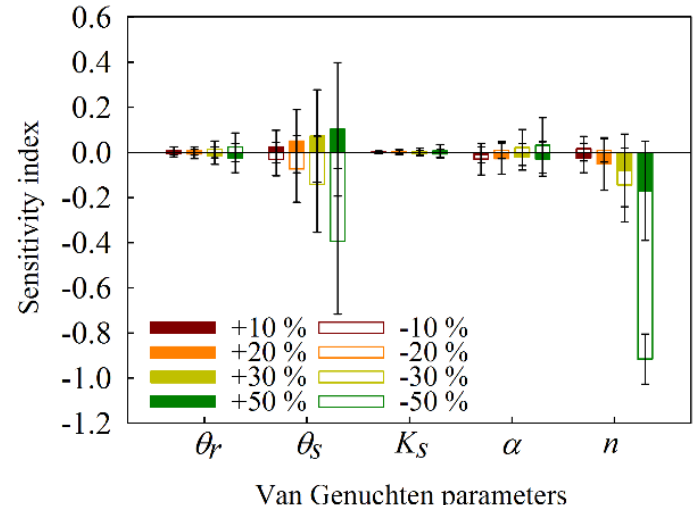

(a) Emergence-jointing stage

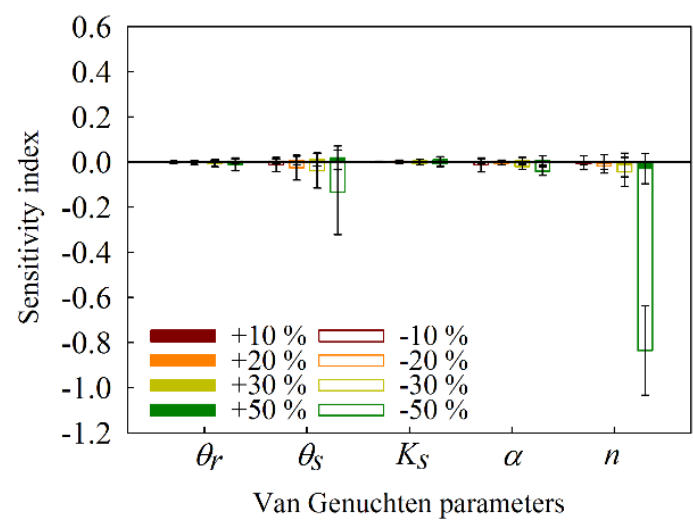

(c) Heading-grouting stage

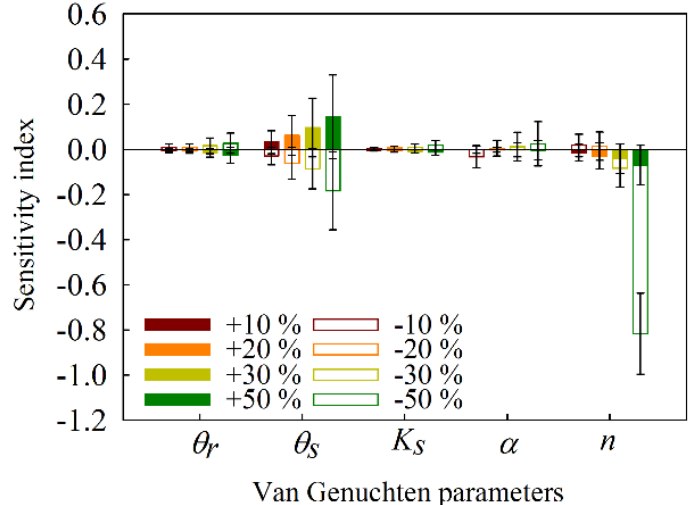

(b) Jointing-heading stage

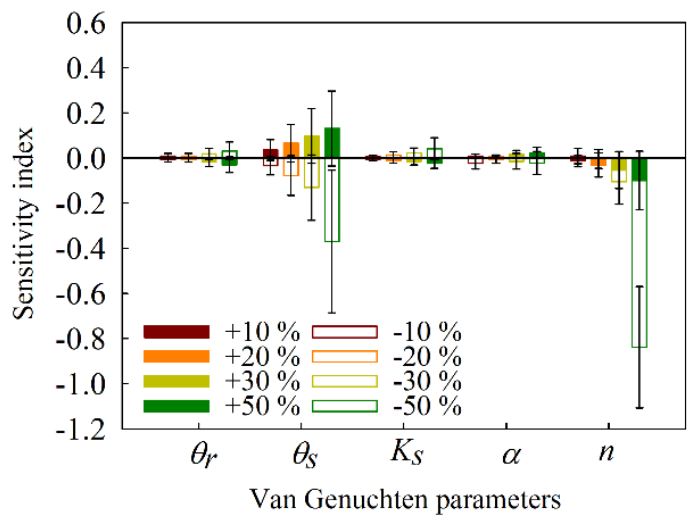

(d) Grouting-maturity stage

Figure 6. (a) Emergence-jointing stage; (b) Jointing-heading stage; (c) Heading-grouting stage; and (d) Grouting-maturity stage.

\subsubsection{Influence of Different Change Ranges on Sensitivity Analysis}

Taking the high sensitivity parameters $\theta_{\mathrm{s}}$ and $\mathrm{n}$ affecting SWC and ET as examples, the influences of different change ranges on the sensitivity analysis were explained.

For SWC in the root zone, the average value and standard deviation of the SI for the two parameters increased with the parameter change range. When the range of change increased from $\pm 10 \%$ to $\pm 50 \%$, the SI of $\theta_{\mathrm{s}}$ increased by $441 \%$ (from $+10 \%$ to $+50 \%$ ) and $396 \%$ (from $-10 \%$ to $-50 \%$ ), respectively. The absolute SI values of $n$ increased by $203 \%$ (from $+10 \%$ to $+50 \%$ ) and $624 \%$ (from $-10 \%$ to $-50 \%)$, respectively.

For ET throughout the growth period, the average value and the standard deviation of the SI of $\theta_{\mathrm{S}}$ increased with the parameter change range. When the range of change increased from $\pm 10 \%$ to $\pm 50 \%$, the SI of $\theta_{\mathrm{s}}$ increased by $306 \%$ (from $+10 \%$ to $+50 \%$ ) and $946 \%$ (from $-10 \%$ to $-50 \%$ ), respectively. The SI of $\mathrm{n}$ varied with the positive and negative parameter change range during the emergence-heading stage. When the positive change gradually increased from $+10 \%$ to $+50 \%$, the absolute SI values increased gradually. When the negative change gradually increased from $-10 \%$ to $-20 \%$, the SI of $n$ gradually decreased from a positive value ( 0.016 and 0.018 , respectively) to -0.144 and -0.083 (when the change was $-30 \%)$. As the negative change increased, the SI of $\mathrm{n}$ further decreased to -0.916 and -0.817 (when the change was $-50 \%$ ). When the negative change gradually increased from $-10 \%$ 
to $-50 \%$, the SI of $\mathrm{n}$ in the heading-maturity stage was always negative, and the absolute SI values increased gradually.

The Savage scores of the VGM parameter were calculated using the sensitivity ranking results under different change ranges in different soil layers (Table 4). Furthermore, we obtained the TDCC coefficient to evaluate the consistency of sensitivity ranking. The results of the sensitivity consistency test for the five parameters under the eight changed conditions are shown in Table 5. The TDCC coefficients of different soil layers exceeded 0.778 (with an average of 0.789 ) and the $P$ values were less than 0.01 . This indicated that the ranking of parameter sensitivity for SWC had extremely significant $(p<0.01)$ consistency under different ranges in the root zone. The Savage scores of the VGM parameter were calculated by the sensitivity ranking results under different change ranges in different growth stages (Table 6). The TDCC coefficients of different growth stages (Table 5) exceeded 0.622 (the average was 0.695$)$ and the $P$ values were all less than 0.01 . This indicated that the ranking of parameter sensitivity for ET had extremely significant $(p<0.01)$ consistency under different ranges throughout the growth period.

Table 4. Ranking of sensitivity index absolute value of the van Genuchten-Mualem model (VGM) parameters for the soil profile water content simulated by SWAP under different parameter change ranges.

\begin{tabular}{|c|c|c|c|c|c|c|c|c|c|}
\hline \multirow{2}{*}{$\begin{array}{l}\text { Soil Layers } \\
\text { (cm) }\end{array}$} & \multirow{2}{*}{$\begin{array}{c}\text { VGM } \\
\text { Parameters }\end{array}$} & \multicolumn{8}{|c|}{ Parameter Change Ranges } \\
\hline & & $+10 \%$ & $+20 \%$ & $+30 \%$ & $+50 \%$ & $-10 \%$ & $-20 \%$ & $-30 \%$ & $-50 \%$ \\
\hline \multirow{5}{*}{$0-20$} & $\theta_{\mathrm{r}}$ & 3 & 3 & 3 & 3 & 4 & 3 & 3 & 3 \\
\hline & $\theta_{\mathrm{s}}$ & 2 & 1 & 1 & 1 & 2 & 2 & 2 & 2 \\
\hline & $K_{s}$ & 5 & 5 & 5 & 5 & 5 & 4 & 5 & 5 \\
\hline & $\alpha$ & 4 & 4 & 4 & 4 & 3 & 5 & 4 & 4 \\
\hline & $\mathrm{n}$ & 1 & 2 & 2 & 2 & 1 & 1 & 1 & 1 \\
\hline \multirow{5}{*}{$20-40$} & $\theta_{\mathrm{r}}$ & 3 & 4 & 3 & 3 & 4 & 3 & 3 & 3 \\
\hline & $\theta_{\mathrm{s}}$ & 1 & 1 & 1 & 1 & 2 & 2 & 2 & 2 \\
\hline & $\mathrm{K}_{\mathrm{s}}$ & 4 & 5 & 4 & 4 & 5 & 4 & 4 & 4 \\
\hline & $\alpha$ & 5 & 3 & 5 & 5 & 3 & 5 & 5 & 5 \\
\hline & $\mathrm{n}$ & 2 & 2 & 2 & 2 & 1 & 1 & 1 & 1 \\
\hline \multirow{5}{*}{$40-60$} & $\theta_{\mathrm{r}}$ & 5 & 3 & 3 & 3 & 4 & 3 & 3 & 3 \\
\hline & $\theta_{\mathrm{s}}$ & 1 & 1 & 1 & 1 & 2 & 2 & 2 & 2 \\
\hline & $\mathrm{K}_{\mathrm{s}}$ & 3 & 4 & 4 & 4 & 5 & 4 & 4 & 4 \\
\hline & $\alpha$ & 4 & 5 & 5 & 5 & 3 & 5 & 5 & 5 \\
\hline & $\mathrm{n}$ & 2 & 2 & 2 & 2 & 1 & 1 & 1 & 1 \\
\hline \multirow{5}{*}{$60-80$} & $\theta_{\mathrm{r}}$ & 5 & 3 & 3 & 3 & 3 & 4 & 3 & 3 \\
\hline & $\theta_{\mathrm{s}}$ & 1 & 1 & 1 & 1 & 2 & 2 & 2 & 2 \\
\hline & $\mathrm{K}_{\mathrm{s}}$ & 3 & 4 & 4 & 4 & 5 & 3 & 4 & 4 \\
\hline & $\alpha$ & 4 & 5 & 5 & 5 & 4 & 5 & 5 & 5 \\
\hline & $\mathrm{n}$ & 2 & 2 & 2 & 2 & 1 & 1 & 1 & 1 \\
\hline \multirow{5}{*}{ 80-100 } & $\theta_{\mathrm{r}}$ & 5 & 3 & 3 & 3 & 3 & 3 & 3 & 3 \\
\hline & $\theta_{\mathrm{s}}$ & 1 & 1 & 1 & 1 & 2 & 2 & 2 & 2 \\
\hline & $\mathrm{K}_{\mathrm{s}}$ & 3 & 4 & 4 & 4 & 5 & 4 & 4 & 4 \\
\hline & $\alpha$ & 4 & 5 & 5 & 5 & 4 & 5 & 5 & 5 \\
\hline & $\mathrm{n}$ & 2 & 2 & 2 & 2 & 1 & 1 & 1 & 1 \\
\hline
\end{tabular}


Table 5. Sensitivity ranking consistency test results of the van Genuchten-Mualem model (VGM) parameters for the soil profile water content and daily evapotranspiration of different stages simulated by SWAP under different parameter change ranges.

\begin{tabular}{ccccc}
\hline Soil Layer/Growth Stage & TDCC & T Value & $p$ Value \\
\hline Soil layers $(\mathrm{cm})$ & $0-20$ & 0.813 & 26.001 & $3.164 \times 10^{-5}$ \\
& $20-40$ & 0.780 & 24.975 & $5.088 \times 10^{-5}$ \\
& $40-60$ & 0.778 & 24.881 & $5.316 \times 10^{-5}$ \\
& $60-80$ & 0.784 & 25.075 & $4.859 \times 10^{-5}$ \\
Growth stages & E0-100 & 0.790 & 25.280 & $4.420 \times 10^{-5}$ \\
& Emergence-jointing & 0.735 & 23.534 & $9.904 \times 10^{-5}$ \\
& Jointing-heading & 0.698 & 22.335 & $1.719 \times 10^{-4}$ \\
& Heading-grouting & 0.622 & 19.912 & $5.199 \times 10^{-4}$ \\
& Grouting-maturity & 0.725 & 23.194 & $1.158 \times 10^{-4}$ \\
\hline
\end{tabular}

Note: TDCC (top-down coefficient of concordance) is the consistency test coefficient; T value is the statistic calculated according to TDCC and approximates the $\chi^{2}$ distribution with a degree of freedom of $n-1(n$ is the number of parameters, the value is 5 in this study, which represents 5 VGM parameters: residual water content $\theta_{\mathrm{r}}$, saturated water content $\theta_{\mathrm{s}}$, saturated hydraulic conductivity $\mathrm{K}_{\mathrm{s}}$, and water content shape factor $\alpha$ and $\mathrm{n}$ ); $p$ value is the result of the saliency analysis. When $p<0.01$, the parameter sensitivity ranking results have extremely significant consistency.

Table 6. Ranking of the sensitivity index absolute values of the van Genuchten-Mualem model (VGM) parameters for daily evapotranspiration of different stages simulated by SWAP under different parameter change ranges.

\begin{tabular}{|c|c|c|c|c|c|c|c|c|c|}
\hline \multirow{2}{*}{ Growth Stages } & \multirow{2}{*}{$\begin{array}{c}\text { VGM } \\
\text { Parameters }\end{array}$} & \multicolumn{8}{|c|}{ Parameter Change Ranges } \\
\hline & & $10 \%$ & $20 \%$ & $30 \%$ & $50 \%$ & $-10 \%$ & $-20 \%$ & $-30 \%$ & $-50 \%$ \\
\hline \multirow{5}{*}{ Emergence-jointing } & $\theta_{\mathrm{r}}$ & 4 & 4 & 4 & 4 & 4 & 4 & 4 & 4 \\
\hline & $\theta_{\mathrm{s}}$ & 1 & 2 & 2 & 2 & 1 & 1 & 2 & 2 \\
\hline & $\mathrm{K}_{\mathrm{s}}$ & 5 & 5 & 5 & 5 & 5 & 5 & 5 & 5 \\
\hline & $\alpha$ & 3 & 3 & 3 & 3 & 2 & 2 & 3 & 3 \\
\hline & $\mathrm{n}$ & 2 & 1 & 1 & 1 & 3 & 3 & 1 & 1 \\
\hline \multirow{5}{*}{ Jointing-heading } & $\theta_{\mathrm{r}}$ & 3 & 3 & 3 & 3 & 4 & 3 & 3 & 3 \\
\hline & $\theta_{\mathrm{s}}$ & 1 & 1 & 1 & 1 & 2 & 1 & 1 & 2 \\
\hline & $\mathrm{K}_{\mathrm{s}}$ & 4 & 4 & 4 & 4 & 5 & 4 & 5 & 5 \\
\hline & $\alpha$ & 5 & 5 & 5 & 5 & 1 & 5 & 4 & 4 \\
\hline & $\mathrm{n}$ & 2 & 2 & 2 & 2 & 3 & 2 & 2 & 1 \\
\hline \multirow{5}{*}{ Heading-grouting } & $\theta_{\mathrm{r}}$ & 4 & 5 & 5 & 3 & 5 & 5 & 5 & 5 \\
\hline & $\theta_{\mathrm{s}}$ & 1 & 1 & 2 & 2 & 2 & 1 & 2 & 2 \\
\hline & $\mathrm{K}_{\mathrm{s}}$ & 5 & 4 & 4 & 4 & 4 & 4 & 4 & 4 \\
\hline & $\alpha$ & 2 & 3 & 3 & 5 & 1 & 3 & 3 & 3 \\
\hline & $\mathrm{n}$ & 3 & 2 & 1 & 1 & 3 & 2 & 1 & 1 \\
\hline \multirow{5}{*}{ Grouting-maturity } & $\theta_{\mathrm{r}}$ & 4 & 4 & 3 & 3 & 3 & 3 & 4 & 4 \\
\hline & $\theta_{\mathrm{s}}$ & 1 & 1 & 1 & 1 & 1 & 1 & 1 & 2 \\
\hline & $\mathrm{K}_{\mathrm{s}}$ & 5 & 3 & 5 & 4 & 5 & 2 & 3 & 3 \\
\hline & $\alpha$ & 3 & 5 & 4 & 5 & 2 & 4 & 5 & 5 \\
\hline & $\mathrm{n}$ & 2 & 2 & 2 & 2 & 4 & 5 & 2 & 1 \\
\hline
\end{tabular}

\subsection{SWAP Model Calibration and Verification}

The SWC simulated by the SWAP model were in good agreement with the measured values (Figure 7). The model could clearly characterize the change of SWC caused by irrigation. The MREs of each treatment were $4.71 \%-21.66 \%$, and the RMSEs were $0.01-0.07 \mathrm{~cm}^{3} \mathrm{~cm}^{-3}$ (Table 7). These values were all within an acceptable range [37]. This meant that the verified SWAP model can be used to accurately predict SWC. 

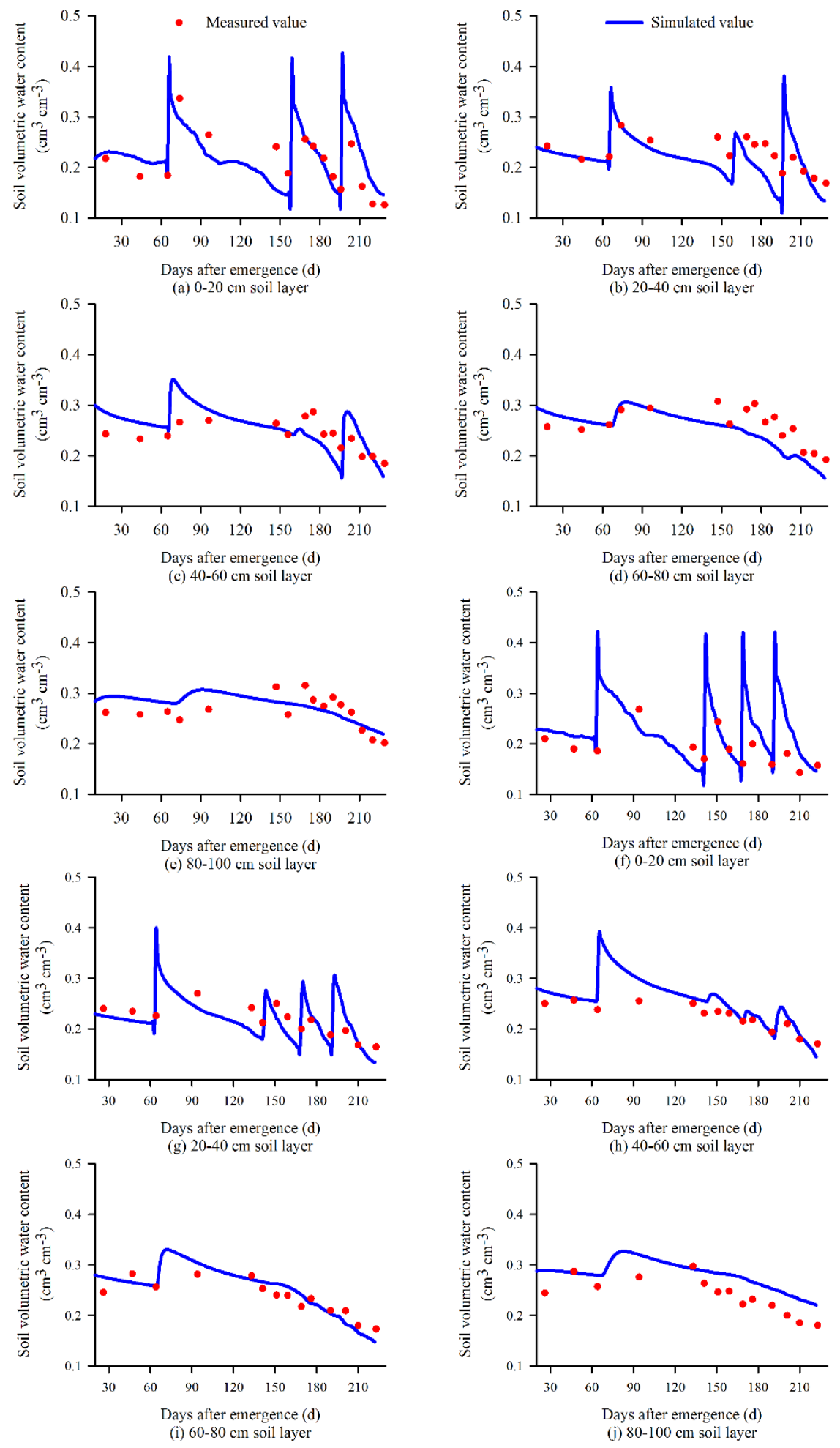

Figure 7. Simulated and observed values of the soil water content of T5 (calibration treatment) and W2 (verification treatment): (a) 0-20 cm soil layer water content of T5; (b) 20-40 cm soil layer water content of T5; (c) 40-60 cm soil layer water content of T5; (d) 60-80 cm soil layer water content of T5; (e) 80-100 cm soil layer water content of T5; (f) 0-20 cm soil layer water content of W2; (g) 20-40 cm soil layer water content of W2; (h) 40-60 cm soil layer water content of W2; (i) 60-80 cm soil layer water content of W2; (j) 80-100 cm soil layer water content of W2. 
Table 7. Average relative error (MRE) and root mean square error (RMSE) of observed and simulated soil water content (SWC) values based on the calibrated SWAP model during the 2012-2013 and 2013-2014 growing seasons.

\begin{tabular}{|c|c|c|c|c|c|c|c|c|c|c|c|}
\hline \multirow{3}{*}{ Year } & \multirow{3}{*}{ Treatments } & \multicolumn{10}{|c|}{ Soil Layers (cm) } \\
\hline & & \multicolumn{2}{|c|}{$0-20$} & \multicolumn{2}{|c|}{$20-40$} & \multicolumn{2}{|c|}{$40-60$} & \multicolumn{2}{|c|}{$60-80$} & \multicolumn{2}{|c|}{$80-100$} \\
\hline & & $\underset{\%}{\operatorname{MRE}}$ & $\begin{array}{c}\text { RMSE } \\
\left(\mathrm{cm}^{3} \mathrm{~cm}^{-3}\right)\end{array}$ & $\underset{\%}{\text { MRE }}$ & $\begin{array}{c}\text { RMSE } \\
\left(\mathrm{cm}^{3} \mathrm{~cm}^{-3}\right)\end{array}$ & $\underset{\%}{\operatorname{MRE}}$ & $\begin{array}{c}\text { RMSE } \\
\left(\mathrm{cm}^{3} \mathrm{~cm}^{-3}\right)\end{array}$ & $\underset{\%}{\text { MRE }}$ & $\begin{array}{c}\text { RMSE } \\
\left(\mathrm{cm}^{3} \mathrm{~cm}^{-3}\right)\end{array}$ & $\underset{\%}{\text { MRE }}$ & $\begin{array}{c}\text { RMSE } \\
\left(\mathrm{cm}^{3} \mathrm{~cm}^{-3}\right)\end{array}$ \\
\hline \multirow{9}{*}{ 2012-2013 } & W1 & 17.59 & 0.04 & 11.12 & 0.03 & 19.11 & 0.05 & 15.39 & 0.04 & 19.19 & 0.05 \\
\hline & W2 & 14.57 & 0.03 & 11.96 & 0.03 & 7.91 & 0.02 & 7.29 & 0.02 & 14.81 & 0.04 \\
\hline & W3 & 14.94 & 0.03 & 16.49 & 0.04 & 13.78 & 0.04 & 6.78 & 0.02 & 14.56 & 0.04 \\
\hline & W4 & 17.36 & 0.04 & 18.52 & 0.04 & 7.44 & 0.02 & 7.08 & 0.02 & 15.78 & 0.04 \\
\hline & W5 & 13.41 & 0.03 & 12.14 & 0.03 & 10.76 & 0.03 & 6.84 & 0.02 & 12.19 & 0.03 \\
\hline & W6 & 13.30 & 0.03 & 14.16 & 0.03 & 10.00 & 0.03 & 6.38 & 0.02 & 10.81 & 0.03 \\
\hline & W7 & 11.77 & 0.03 & 11.39 & 0.03 & 7.36 & 0.02 & 6.08 & 0.02 & 13.46 & 0.03 \\
\hline & W8 & 12.77 & 0.03 & 12.01 & 0.03 & 9.40 & 0.03 & 5.00 & 0.02 & 9.99 & 0.03 \\
\hline & W9 & 12.26 & 0.03 & 15.53 & 0.04 & 8.62 & 0.02 & 12.55 & 0.04 & 4.75 & 0.01 \\
\hline \multirow{7}{*}{ 2013-2014 } & $\mathrm{T} 1$ & 6.92 & 0.02 & 16.10 & 0.04 & 9.22 & 0.03 & 14.82 & 0.05 & 11.83 & 0.04 \\
\hline & $\mathrm{T} 2$ & 11.82 & 0.03 & 17.92 & 0.05 & 17.00 & 0.05 & 20.71 & 0.07 & 11.08 & 0.04 \\
\hline & $\mathrm{T} 3$ & 9.73 & 0.03 & 21.97 & 0.06 & 19.22 & 0.05 & 14.59 & 0.04 & 4.71 & 0.02 \\
\hline & $\mathrm{T} 4$ & 8.92 & 0.03 & 19.51 & 0.05 & 16.36 & 0.05 & 18.13 & 0.05 & 12.09 & 0.04 \\
\hline & $\mathrm{T} 5$ & 16.26 & 0.04 & 14.81 & 0.04 & 13.35 & 0.04 & 11.39 & 0.04 & 9.08 & 0.03 \\
\hline & $\mathrm{T} 8$ & 9.11 & 0.03 & 21.77 & 0.05 & 17.68 & 0.05 & 20.16 & 0.06 & 8.11 & 0.03 \\
\hline & $\mathrm{T} 9$ & 15.07 & 0.04 & 18.54 & 0.05 & 13.87 & 0.04 & 11.20 & 0.03 & 10.32 & 0.03 \\
\hline
\end{tabular}




\subsection{Water Balance under Deficit Irrigation}

\subsubsection{Pattern of Soil Water}

During the period of no irrigation, the water flux of the surface soil was mainly positive due to soil evaporation (Figure 8). As the experiment progressed, the positive water flux gradually extended to the deep soil. The soil water flux was negative under irrigation, and the greater the irrigation amount, the larger the negative water flux in the lower soil layers. At the heading-grouting stage, the irrigation amount of the T1 treatment was 40\% higher than that of T8. The average water flux of $\mathrm{T} 1$ in the root zone was negative. The T8 treatment only maintained the water flux of $-0.035 \mathrm{~mm}$ $\mathrm{d}^{-1}$ in the $60 \mathrm{~cm}$ soil layer; however, the flux in the deeper soil had become positive. In addition, the experiment excluded the influences of precipitation, making irrigation and soil storage water the two main sources of water consumption in the winter wheat field. Since the deficit irrigation did not meet the demand of crop ET, all treatments needed to consume 15.99-35.58\% of water stored in the soil (Table 8 ). The deep percolations of all treatments were positive (the average is $14.54 \mathrm{~mm}$ ), and the total deep percolation generally increased with irrigation. However, some treatments did not conform to this pattern. For example, irrigation of W3 was $24 \mathrm{~mm}$ less than W9, and the deep percolation of W3 was $16.72 \mathrm{~mm}$ higher than the latter. This was also observed in many treatments during the 2013-2014 growing season.
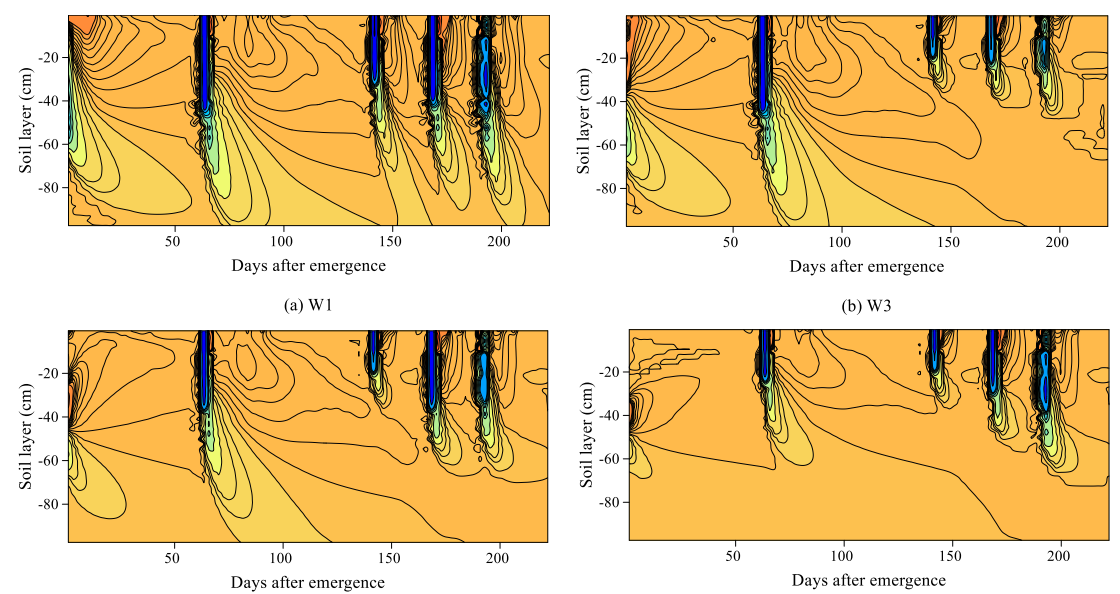

(c) W6

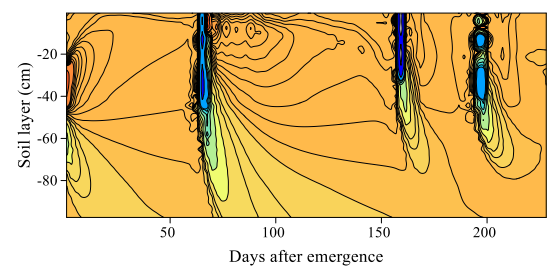

(d) $\mathrm{W} 9$

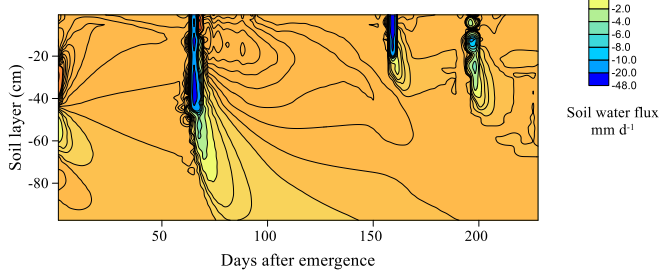

(e) $\mathrm{T}$

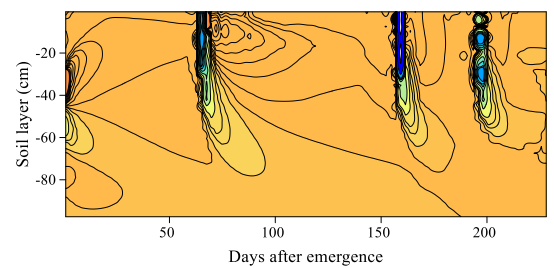

(g) $\mathrm{T} 7$

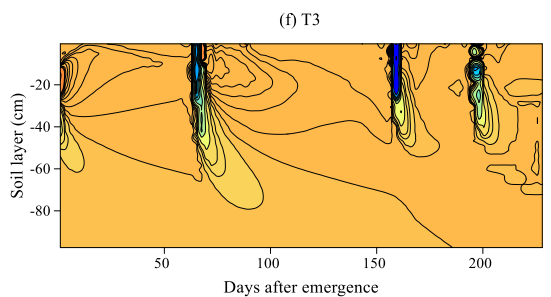

(h) $\mathrm{T} 8$

Figure 8. Contour map of soil profile water flux with growth stage during the 2012-2013 and 2013-2014 growing seasons. (a) W1 treatment; (b) W3 treatment; (c) W6 treatment; (d) W9 treatment; (e) T1 treatment; (f) T3 treatment; (g) T7 treatment; and (h) T8 treatment. Positive water flux represents water moving upward and a negative water flux represents water moving downward. 
Table 8. Composition of the field water simulated by SWAP model under different irrigation treatments during the 2012-2013 and 2013-2014 growing seasons.

\begin{tabular}{cccccccccc}
\hline Year & Treatments & $\mathbf{D}$ & $\mathbf{\Delta W}$ & $\mathbf{E T}$ & Year & Treatments & $\mathbf{D}$ & $\boldsymbol{\Delta W}$ & ET \\
\hline W1 & 19.42 & -72.05 & 389.63 & & T1 & 36.86 & -91.03 & 318.17 \\
W2 & 33.54 & -108.84 & 361.31 & & T2 & 23.44 & -96.36 & 300.92 \\
W3 & 18.24 & -112.88 & 329.64 & & T3 & 19.15 & -95.46 & 268.31 \\
$2012-2013$ & W4 & 5.86 & -84.72 & 346.86 & & T4 & 15.07 & -95.07 & 285.00 \\
& W5 & 11.90 & -90.08 & 349.18 & $2013-2014$ & T5 & 26.65 & -109.13 & 314.49 \\
& W6 & 11.60 & -91.36 & 353.76 & & T6 & 7.60 & -68.65 & 257.05 \\
& W7 & 7.95 & -95.17 & 340.23 & & T7 & 6.01 & -82.38 & 287.37 \\
W8 & 5.58 & -77.47 & 327.89 & & T8 & 4.05 & -86.58 & 257.53 \\
& W9 & 1.51 & -49.02 & 306.51 & & T9 & 7.37 & -89.66 & 284.29 \\
\hline
\end{tabular}

Note: D represents deep percolation $(\mathrm{mm}) ; \Delta \mathrm{W}$ represents change of soil water storage $(\mathrm{mm})$; ET represents evapotranspiration $(\mathrm{mm})$.

\subsubsection{Pattern of ET}

The simulated ET in the entire growth period was $257.05-389.63 \mathrm{~mm}$, which had good agreement $\left(R^{2}=0.975, p<0.01\right)$ with the calculated value (Figure 9). In general, ET was positively correlated with the amount of irrigation in the same year. The difference in ET between two growing seasons was large. For example, the irrigation amount of T5 was $10.42 \%$ lower than that of W9, but the ET was $7.97 \mathrm{~mm}$ higher. The daily ET of winter wheat increased first and then decreased with growth (Figure 10). The promotion effect of irrigation on ET was clear, and the daily ET reached the peak value after $2-11 \mathrm{~d}$ of irrigation. The maximum ET of the two-year test was $7.75 \mathrm{~mm} \mathrm{~d}^{-1}$ (12 May 2013) and $6.21 \mathrm{~mm} \mathrm{~d}^{-1}$ (19 May 2014), both occurring in the grouting-maturation stage. The daily ET of different growth stages varied greatly. The average values of each growth period in 2012-2013 were $0.63 \mathrm{~mm} \mathrm{~d}^{-1}, 2.64 \mathrm{~mm} \mathrm{~d}^{-1}, 3.56 \mathrm{~mm} \mathrm{~d}^{-1}$ and $3.30 \mathrm{~mm} \mathrm{~d}^{-1}$; those in 2013-2014 were $0.55 \mathrm{~mm} \mathrm{~d}^{-1}$, $1.95 \mathrm{~mm} \mathrm{~d}^{-1}, 3.01 \mathrm{~mm} \mathrm{~d}^{-1}$ and $3.11 \mathrm{~mm} \mathrm{~d}^{-1}$. With respect to cumulative ET, the early growth stage increased slowly. During the jointing stage (approximately 150 days after emergence), the winter wheat entered the rapid growth stage and the cumulative ET increased.

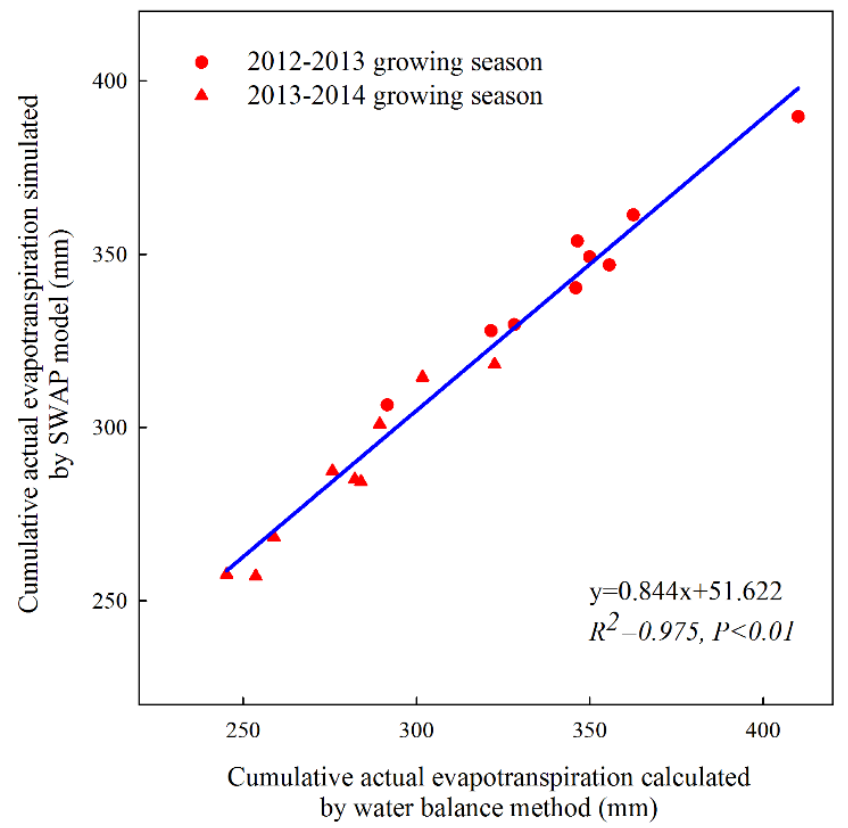

Figure 9. Comparison of simulated and calculated cumulative evapotranspiration during the entire growth period of the 2012-2013 and 2013-2014 growing seasons. 


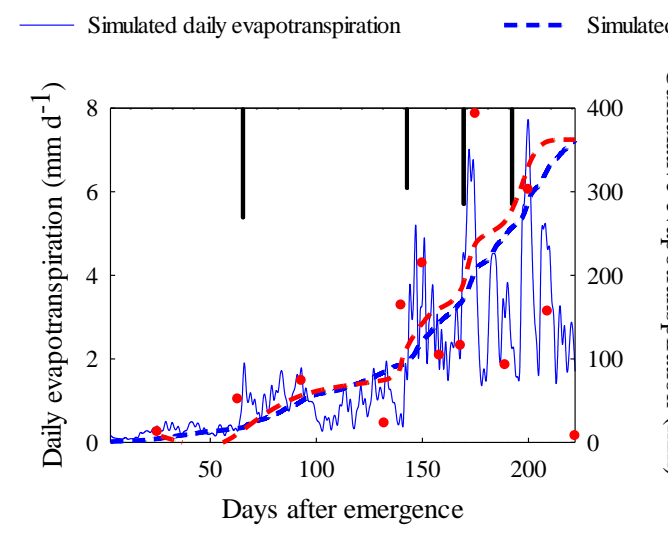

(a) $\mathrm{W} 2$

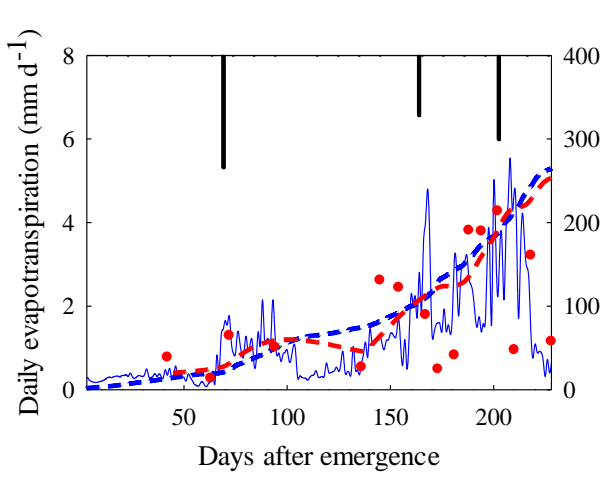

(d) $\mathrm{T} 3$

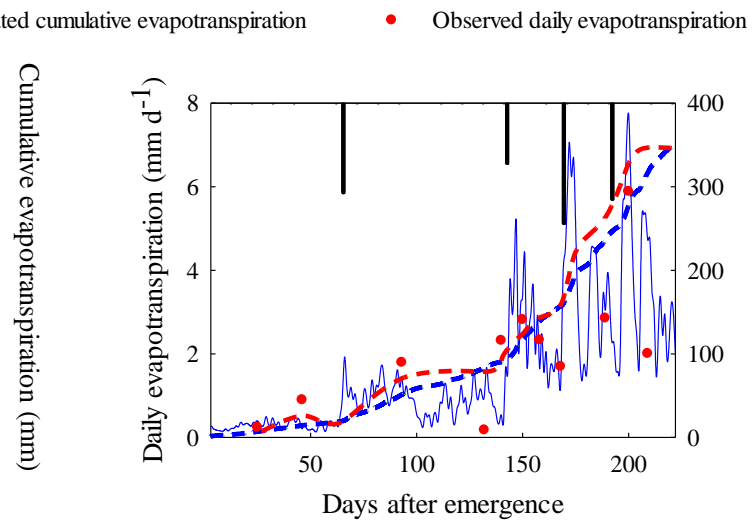

(b) W6
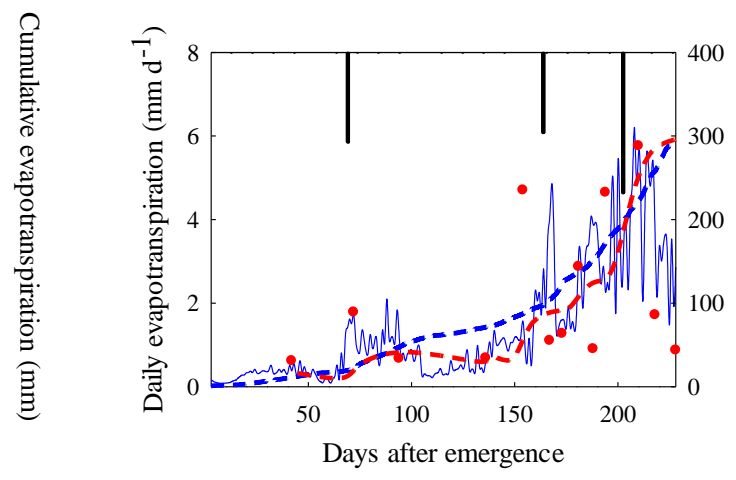

(e) $\mathrm{T} 5$

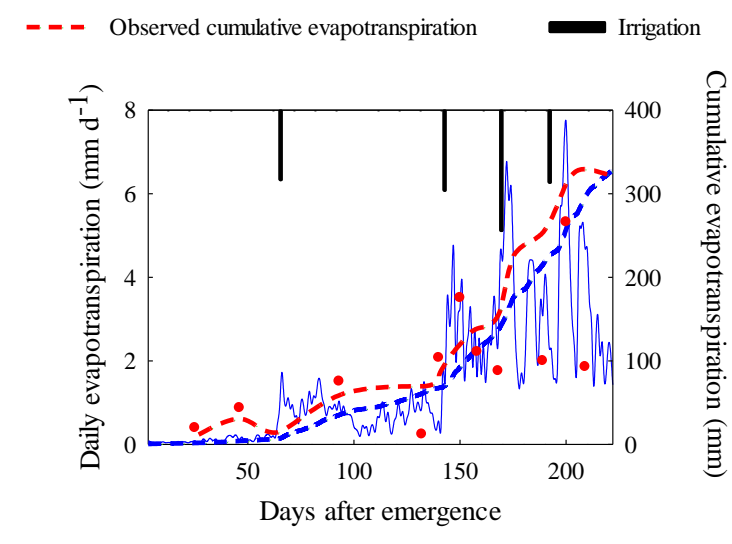

(c) W8

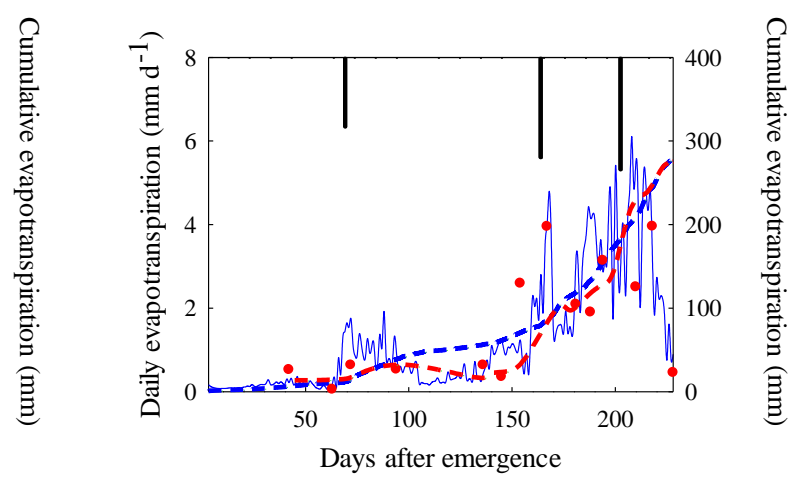

(f) $\mathrm{T} 7$

Figure 10. Comparison of simulated and observed daily and cumulative evapotranspiration and irrigation amounts for different growth stages during the 2012-2013 and 2013-2014 growing seasons. (a) W2 treatment; (b) W6 treatment; (c) W8 treatment; (d) T3 treatment; (e) T5 treatment; and (f) T7 treatment. 
$\mathrm{T}_{\mathrm{a}}$ of the two-year test accounted for $88.40 \%$ of the total water consumption, which was the main consumption for the entire growth stage of winter wheat. $T_{a}$ increased gradually with the growth period, while $E_{a}$ was the opposite (Table 9). Irrigation had a great influence on $T_{a}$ but limited effects on $\mathrm{E}_{\mathrm{a}}$. For instance, the difference in $\mathrm{T}_{\mathrm{a}}$ between $\mathrm{W} 3$ and $\mathrm{W} 8$ reached $30.47 \%$ at the grouting-mature stage. However, $E_{a}$ was stable at $6.96 \mathrm{~mm}$. The effects of water stress on ET of the rewetting stage were different. For example, W1 and W7 received the same irrigation amount at the jointing-heading stage, and the difference in ET was only $0.68 \mathrm{~mm}$. The irrigation amount of T5 at the jointing-heading stage was $20 \%$ lower than that of T7. The irrigation in T5 at the heading-grouting stage was $20 \%$ higher than that in T7, but the ET at the heading-grouting stage was $6.43 \%$ lower than that in T7. The situation was similar for W4 and W8, and W7 and W9. In the case of water stress during the heading-grouting stage and rewetting during the grouting-mature period, the above phenomenon still existed but was weakened. For example, irrigation of W9 during the heading-grouting stage was 20\% lower than that of W6. W9 was irrigated more during the grouting-mature stage, while ET of this stage was $1.89 \%$ lower than that of W6. W5 and W6, W7 and W8 showed similar results.

Table 9. Actual plant transpiration $\left(\mathrm{T}_{\mathrm{a}}\right)$ and actual soil evaporation $\left(\mathrm{E}_{\mathrm{a}}\right)$ at different growth stages during the 2012-2013 and 2013-2014 growing seasons.

\begin{tabular}{|c|c|c|c|c|c|c|c|c|c|}
\hline \multirow{2}{*}{ Year } & \multirow{2}{*}{ Treatments } & \multicolumn{2}{|c|}{ Emergence-Jointing } & \multicolumn{2}{|c|}{ Jointing-Heading } & \multicolumn{2}{|c|}{ Heading-Grouting } & \multicolumn{2}{|c|}{ Grouting-Maturity } \\
\hline & & $T_{a}$ & $E_{a}$ & $T_{a}$ & $E_{a}$ & $T_{a}$ & $E_{a}$ & $T_{a}$ & $E_{a}$ \\
\hline \multirow[t]{9}{*}{ 2012-2013 } & W1 & 64.24 & 51.40 & 58.12 & 10.66 & 65.19 & 16.39 & 114.53 & 9.10 \\
\hline & W2 & 73.32 & 20.51 & 64.78 & 7.42 & 69.34 & 12.65 & 105.15 & 8.15 \\
\hline & W3 & 76.18 & 38.12 & 57.35 & 6.68 & 59.00 & 12.35 & 72.95 & 7.01 \\
\hline & W4 & 73.07 & 16.69 & 70.70 & 6.88 & 72.79 & 11.30 & 88.26 & 7.17 \\
\hline & W5 & 67.62 & 23.19 & 61.91 & 8.49 & 60.11 & 12.81 & 106.58 & 8.46 \\
\hline & W6 & 70.85 & 20.12 & 59.45 & 5.99 & 68.17 & 12.71 & 108.65 & 7.83 \\
\hline & W7 & 60.50 & 23.23 & 58.90 & 10.35 & 64.92 & 12.95 & 101.82 & 7.57 \\
\hline & W8 & 52.21 & 16.13 & 57.77 & 10.11 & 64.30 & 15.51 & 104.92 & 6.93 \\
\hline & W9 & 45.76 & 11.31 & 54.01 & 7.04 & 60.55 & 13.58 & 105.57 & 8.70 \\
\hline \multirow[t]{9}{*}{ 2013-2014 } & T1 & 71.77 & 16.01 & 45.37 & 4.38 & 86.00 & 4.02 & 87.17 & 3.46 \\
\hline & T2 & 79.88 & 13.28 & 45.38 & 3.52 & 79.04 & 2.65 & 75.27 & 1.90 \\
\hline & $\mathrm{T} 3$ & 81.79 & 15.38 & 45.49 & 3.48 & 63.52 & 2.55 & 53.91 & 2.19 \\
\hline & $\mathrm{T} 4$ & 75.66 & 12.03 & 44.51 & 4.03 & 83.40 & 3.58 & 59.87 & 1.91 \\
\hline & T5 & 77.38 & 14.17 & 45.45 & 3.61 & 78.80 & 3.07 & 89.57 & 2.45 \\
\hline & $\mathrm{T} 6$ & 58.55 & 7.80 & 45.74 & 3.80 & 64.66 & 2.54 & 71.28 & 2.68 \\
\hline & $\mathrm{T} 7$ & 65.61 & 8.87 & 44.11 & 3.68 & 83.59 & 3.54 & 75.61 & 2.36 \\
\hline & $\mathrm{T} 8$ & 70.75 & 9.85 & 43.33 & 4.40 & 72.99 & 3.09 & 50.94 & 2.17 \\
\hline & T9 & 65.79 & 14.89 & 44.73 & 4.05 & 63.62 & 2.97 & 85.45 & 2.79 \\
\hline
\end{tabular}

Note: the unit of $T_{a}$ and $E_{a}$ is $m m$.

\subsection{Establishment and Verification of the ET Estimation Model}

\subsubsection{Correlation and Path Analysis of ET}

In order to screen out the main influential factors of ET, the meteorological factors: radiation (10_RAD), wind speed at $2 \mathrm{~m}$ (X11_U2), relative humidity $\left(\mathrm{X} 9 \_\mathrm{RH}\right)$, average temperature $\left(\mathrm{X} 8 \_\mathrm{T}\right)$; crop factors: crop height $\left(\mathrm{X} 2 \_\mathrm{CH}\right)$ and leaf area index $\left(\mathrm{X} 1 \_\mathrm{LAI}\right)$; soil factors: average volume SWC of each soil layer (X3_SWC20, X4_SWC40, X5_SWC60, X6_SWC80, X7_SWC100) were taken as independent variables. The simulated daily ET was taken as a dependent variable (Y_ET). Subsequently, a stepwise linear regression was performed. The multivariate linear regression estimated the daily ET well $\left(R^{2}=0.815, p<0.01\right)$ after removing the X4_SWC40 and X7_SWC100. However, the estimation model requires too many parameters. By running the path analysis, the number of parameters needed for estimation model can be reduced which would lead to model simplification. The results of the correlation (Table 10) and path analysis (Table 11) showed that, except for X9_RH and X6_SWC80, the direct effect coefficients (DE) of other factors for daily ET were positive. The absolute DE of X2_CH, 
X10_RAD, X5_SWC60, X9_RH and X6_SWC80 for daily ET were all greater than 0.100. They had large direct influences on Y_ET, and the ranking of influence was: X2_CH (0.545) > X5_SWC60 $(0.420)>$ X10_RAD $(0.340)>$ X6_SWC80 $(-0.185)>$ X9_RH $(-0.117)$. From the perspective of the total indirect effect coefficients (IE), except for X5_SWC60 and X9_RH, the IE of other factors on daily ET was positive. The simple correlation coefficient (CC) with the dependent variable was equal to the sum of the DE and the total IE. Except for X5_SWC60 and X6_SWC80, the influence of other factors on the Y_ET was enhanced by the IE (compared with the absolute DE, the absolute CC increased). The strong positive DE of X5_SWC60 on ET was mainly obscured by the negative IE of X2_CH $(-0.213)$ and X6_SWC80 (-0.181). This resulted in a reduced CC between X5_SWC60 and Y_ET. The CC between X1_LAI, X8_T and Y_ET was enhanced by the IE of X2_CH (0.448 and 0.431, respectively) and X10_RAD (0.146 and 0.235, respectively). The total DC reflects the comprehensive effect of the independent variable on the dependent variable (Table 12). The DC of the error term was small (0.029), indicating that the variables affecting Y_ET were considered comprehensively in the path analysis. The absolute DC of meteorological factors was X10_RAD (0.359) > X8_T (0.089) > X9_RH $(0.043)>$ X11_U2 (0.032); the crop factors was X2_CH $(0.550)>$ X1_LAI (0.084); and the soil factors was X5_SWC60 $(-0.235)>$ X6_SWC80 (0.029) > X3_SWC20 (0.021).

\subsubsection{Establishment and Verification of Crop and Water Stress Coefficient Estimation Model}

According to the DC ranking mentioned above, the first factor was selected from the crop and soil factors, namely, X2_CH and X5_SWC60 were used to construct the respective crop and water stress coefficient estimation models.

The reference crop ET (ET $)$ for the 2012-2013 and 2013-2014 growing seasons was calculated using the Penman-Monteith method [28]. ET of the contrasting treatment was divided by $\mathrm{ET}_{0}$ to obtain the crop coefficient $\left(K_{c}\right)$. We obtained the relationship between $\mathrm{CH}$ and $\mathrm{K}_{c}$ through curve estimation $\left(R^{2}=0.425, p<0.01\right)$ :

$$
K_{c}=0.250 \mathrm{CH}^{0.311}
$$

where $\mathrm{K}_{\mathrm{c}}$ is the crop coefficient $(-)$ and $\mathrm{CH}$ is the crop height of winter wheat $(\mathrm{cm})$.

The ET of deficit irrigation was divided by ET of sufficient irrigation (W1 and T1) to obtain a water stress coefficient $\left(K_{\theta}\right)$. In order to avoid the influence of soil texture, and increase the applicability of the fitting equation, we took the relative water content (the ratio of SWC to field water capacity, RWC) of the $0-60 \mathrm{~cm}$ soil layer as the independent variable and $K_{\theta}$ as the dependent variable, and the following regression model was obtained by curve estimation analysis of all deficit irrigation treatments $\left(R^{2}=0.357, p<0.01\right)$ :

$$
K_{\theta}=-0.983 R W C^{2}+2.44 R W C
$$

where $K_{\theta}$ is the water stress coefficient (-) and RWC is the relative water content of the $0-60 \mathrm{~cm}$ soil layer $\left(\mathrm{cm}^{3} \mathrm{~cm}^{-3}\right)$.

Based on Equations (12) and (13), the following ET estimation model was constructed:

$$
E T_{c}=E T_{0} \times\left(a C H^{b}\right) \times\left(c R W C^{2}+d R W C\right)
$$

where $a, b, c$ and $d$ are empirical coefficients. 
Table 10. Correlation coefficients $\left(r_{i j}\right)$ of main factors affecting evapotranspiration.

\begin{tabular}{|c|c|c|c|c|c|c|c|c|c|c|}
\hline & X2_CH & X10_RAD & X5_SWC60 & X11_U2 & X9_RH & X6_SWC80 & X1_LAI & X8_T & X3_SWC20 & Y_ET \\
\hline X2_CH & 1 & 0.561 ** & $-0.390 * *$ & $0.128^{* *}$ & $0.047^{* *}$ & -0.483 ** & $0.823^{* *}$ & $0.790 * *$ & $-0.034 *$ & $0.777^{* *}$ \\
\hline X10_RAD & & 1 & $-0.294^{* *}$ & $0.069 * *$ & $-0.301^{* *}$ & $-0.346^{* *}$ & $0.430^{* *}$ & $0.690^{* *}$ & $-0.124^{* *}$ & $0.698^{* *}$ \\
\hline X5_SWC60 & & & 1 & $-0.062^{* *}$ & $-0.128^{* *}$ & $0.977^{* *}$ & $-0.377^{* *}$ & $-0.438^{* *}$ & $0.856^{* *}$ & $-0.070^{* *}$ \\
\hline X11_U2 & & & & 1 & $-0.239 * *$ & $-0.072 * *$ & $0.078^{* *}$ & $0.146^{* *}$ & $-0.037^{*}$ & $0.216^{* *}$ \\
\hline X9_RH & & & & & 1 & $-0.139 * *$ & $0.077^{* *}$ & -0.004 & $-0.067^{* *}$ & $-0.243^{* *}$ \\
\hline X6_SWC80 & & & & & & 1 & $-0.456^{* *}$ & $-0.532 * *$ & $0.762 * *$ & $-0.170 * *$ \\
\hline X1_LAI & & & & & & & 1 & $0.649^{* *}$ & $-0.046^{* *}$ & $0.630^{* *}$ \\
\hline X'- & & & & & & & & 1 & $-0.156^{* *}$ & $0.698^{* *}$ \\
\hline X3_SWC20 & & & & & & & & & 1 & $0.207^{* *}$ \\
\hline Y1_ET & & & & & & & & & & 1 \\
\hline
\end{tabular}

Note: $r_{i j}$ represents the correlation coefficient between the $i_{\text {th }}$ variable and the $j_{\text {th }}$ variable; Dependent variable: $Y_{-}$ET; Independent variables: $\mathrm{X} 2 \_C H$ represents crop height (cm);

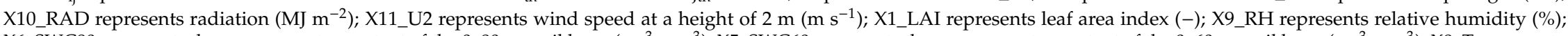
X6_SWC80 represents the average water content of the $0-80 \mathrm{~cm}_{\text {soil layer }}\left(\mathrm{cm}^{3} \mathrm{~cm}^{-3}\right)$; X5_SWC60 represents the average water content of the $0-60 \mathrm{~cm}_{-}$soil layer $\left(\mathrm{cm}^{3} \mathrm{~cm}^{-3}\right)$; X8_T represents the average temperature $\left({ }^{\circ} \mathrm{C}\right)$; X3_SWC20 represents the average water content of the $0-20 \mathrm{~cm}$ soil layer $\left(\mathrm{cm}^{3} \mathrm{~cm}^{-3}\right)$; ${ }^{* *}$ represents significant difference at $p<0.01$; ${ }^{*}$ represents significant difference at $p<0.05$. The footnotes of this table also apply to Tables 11 and 12 .

Table 11. Path analysis results of the main factors affecting evapotranspiration.

\begin{tabular}{|c|c|c|c|c|c|c|c|c|c|c|c|c|}
\hline \multirow{2}{*}{$\begin{array}{l}\text { Independent } \\
\text { Variables }\end{array}$} & \multirow{2}{*}{$\mathrm{CC}$} & \multirow{2}{*}{ DE } & \multicolumn{9}{|c|}{ IE } & \multirow{2}{*}{ Total IE } \\
\hline & & & $\mathrm{X} 2 \_\mathrm{CH}$ & X10_RAD & X5_SWC60 & X11_U2 & X9_RH & X6_SWC80 & X1_LAI & X8_T & X3_SWC20 & \\
\hline $\mathrm{X} 2 \_\mathrm{CH}$ & $0.777^{* *}$ & 0.545 & & 0.191 & -0.164 & 0.012 & -0.005 & 0.089 & 0.058 & 0.053 & -0.002 & 0.232 \\
\hline X10_RAD & $0.698^{* *}$ & 0.340 & 0.306 & & -0.124 & 0.007 & 0.035 & 0.064 & 0.030 & 0.046 & -0.007 & 0.357 \\
\hline X5_SWC60 & $-0.070 * *$ & 0.420 & -0.213 & -0.100 & & -0.006 & 0.015 & -0.181 & -0.027 & -0.029 & 0.050 & -0.490 \\
\hline X11_U2 & $0.216^{* *}$ & 0.094 & 0.070 & 0.023 & -0.026 & & 0.028 & 0.013 & 0.006 & 0.010 & -0.002 & 0.122 \\
\hline X9_RH & -0.243 ** & -0.117 & 0.026 & -0.102 & -0.054 & -0.023 & & 0.026 & 0.005 & 0.000 & -0.004 & -0.126 \\
\hline X6_SWC80 & $-0.170 * *$ & -0.185 & -0.263 & -0.118 & 0.411 & -0.007 & 0.016 & & -0.032 & -0.036 & 0.045 & 0.016 \\
\hline X1_LAI & $0.630^{* *}$ & 0.071 & 0.448 & 0.146 & -0.158 & 0.007 & -0.009 & 0.084 & & 0.044 & -0.003 & 0.560 \\
\hline X8_T & $0.698^{* *}$ & 0.067 & 0.431 & 0.235 & -0.184 & 0.014 & 0.000 & 0.099 & 0.046 & & -0.009 & 0.630 \\
\hline X3_SWC20 & $0.207^{* *}$ & 0.059 & -0.019 & -0.042 & 0.360 & -0.003 & 0.008 & -0.141 & -0.003 & -0.010 & & 0.149 \\
\hline
\end{tabular}

Note: CC represents the simple correlation coefficient between independent and dependent variables; DE represents the direct effect coefficient of independent variables on the dependent variable; IE represents the indirect effect coefficient of independent variables on the dependent variable; Total IE represents the sum of the indirect effect coefficient of the independent variables on the dependent variable; ${ }^{* *}$ represents significant difference at $p<0.01$. 
Table 12. Decision coefficients of main factors affecting evapotranspiration.

\begin{tabular}{|c|c|c|c|c|c|c|c|c|c|c|}
\hline \multirow{2}{*}{$\begin{array}{l}\text { Independent } \\
\text { Variables }\end{array}$} & \multicolumn{9}{|c|}{ DC } & \multirow{2}{*}{ Total DC } \\
\hline & X2_CH & X10_RAD & X5_SWC60 & X11_U2 & X9_RH & X6_SWC80 & X1_LAI & X8_T & X3_SWC20 & \\
\hline $\mathrm{X} 2 \_\mathrm{CH}$ & 0.297 & 0.208 & -0.179 & 0.013 & -0.006 & 0.098 & 0.063 & 0.058 & -0.002 & 0.550 \\
\hline X10_RAD & & 0.116 & -0.084 & 0.004 & 0.024 & 0.044 & 0.021 & 0.032 & -0.005 & 0.359 \\
\hline X5_SWC60 & & & 0.177 & -0.005 & 0.013 & -0.152 & -0.022 & -0.025 & 0.042 & -0.235 \\
\hline X11_U2 & & & & 0.009 & 0.005 & 0.003 & 0.001 & 0.002 & 0.000 & 0.032 \\
\hline X9_RH & & & & & 0.014 & -0.006 & -0.001 & 0.000 & 0.001 & 0.043 \\
\hline X6_SWC80 & & & & & & 0.034 & 0.012 & 0.013 & -0.017 & 0.028 \\
\hline X1_LAI & & & & & & & 0.005 & 0.006 & 0.000 & 0.084 \\
\hline X8_T & & & & & & & & 0.005 & -0.001 & 0.089 \\
\hline X3_SWC20 & & & & & & & & & 0.003 & 0.021 \\
\hline $\mathrm{e}$ & & & & & & & & & & 0.029 \\
\hline
\end{tabular}

Note: DC represents the decision coefficient, which is an evaluation index of the comprehensive effect of independent variables on dependent variables. Total DC represents the sum of the decision coefficients of different independent variables on the dependent variable; e represents the error term in the path analysis, and the smaller the decision coefficient, the more comprehensive the factors affecting evapotranspiration. 


\subsubsection{Parameter Estimation and Verification of the ET Estimation Model}

The coefficients of the independent variables in Equations (12) and (13) were taken as initial values, and the parameters of Equation (14) were estimated by multivariate nonlinear regression analysis of SPSS. After several iterations, the obtained parameter values were $a=0.791, b=-0.002, c=-2.463$, $d=3.610\left(R^{2}=0.996\right)$. The parameter estimation results were substituted into Equation (14) to calculate the daily ET. Figure 11 compares the calculated values and outputs of the SWAP model, showing good agreement $\left(\mathrm{R}^{2}=0.727, p<0.01\right)$. This estimation model provides an effective method for estimating actual ET under deficit irrigation through a few easy-to-measure indicators.

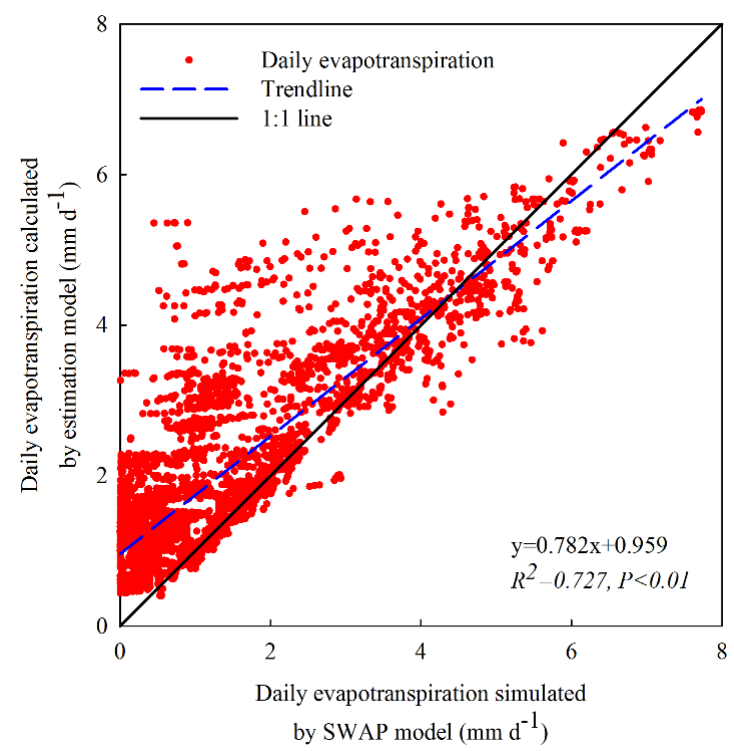

Figure 11. Comparison of daily evapotranspiration (all treatments) simulated by the SWAP model and calculated values during the 2012-2013 and 2013-2014 growing seasons.

\section{Discussion}

From the sensitivity analysis of VGM parameters, SWC and ET were more sensitive to $\theta_{\mathrm{S}}$ and $\mathrm{n}$, while $\theta_{\mathrm{r}}, \mathrm{K}_{\mathrm{s}}$ and $\alpha$ were relatively less sensitive. This is consistent with the results of Sun [45] and slightly different from those of Singh et al. [61]. This may be because $\mathrm{n}$ is the exponential term of the VGM function [28], and $\theta_{\mathrm{s}}$ is the main influential factor of the exponential product term. Thus, small changes of $\theta_{\mathrm{S}}$ and $\mathrm{n}$ have a great impact on SWC. The standard deviation of SI for $\theta_{\mathrm{S}}$ and $\mathrm{n}$ show an increasing trend with an increase in the range of the parameter changes. Therefore, we should control the parameter adjustment within a reasonable range based on the results of previous studies $[49,50]$. This avoids large deviations between the model output and the observed values. In particular, when the range of parameter changes reaches $-50 \%, \mathrm{n}$ is already close to the minimum threshold of 1.001. Therefore, it is not recommended to take $\mathrm{n}$ around this value. According to previous research results, $\theta_{\mathrm{r}}, \mathrm{K}_{\mathrm{s}}$ and $\alpha$ have a large range of reference values. Therefore, $\theta_{\mathrm{s}}$ and $\mathrm{n}$ should be adjusted preferentially when the model parameters are calibrated, and then $\theta_{\mathrm{r}}, \mathrm{K}_{\mathrm{s}}$ and $\alpha$ are adjusted appropriately based on the initial range of values. This can effectively shorten the time of model calibration and also further improve the simulation accuracy.

The simulated SWC in this study was generally accurate. However, the simulation accuracy of deep SWC was better than that of shallow soil. The average MRE of 0-60 cm and $60-100 \mathrm{~cm}$ soil layers were $13.94 \%$ and $11.81 \%$, respectively. This may be related to the variability of water content in different soil layers. The SWC of the 0-60 cm soil layer varied greatly, which was consistent with Ma et al. [31], who believed that the combined effect of irrigation and ET was more likely to affect the water content of the upper soil. In addition, the surface soil was in close contact with the atmosphere. According to 
research results of Wang et al. [23], soil evaporation was greatly affected by temperature, radiation and ground cover, which was likely to cause changes in SWC. Furthermore, the root activity area of winter wheat was concentrated in the $0-40 \mathrm{~cm}$ soil layer [62]. After rewetting, the root activity was stimulated, and the water absorption intensity was enhanced $[55,63,64]$, resulting in a reduction in SWC. However, the $60-100 \mathrm{~cm}$ soil layer had a small change throughout the growth stage. The irrigation amount of the T2 and T7 treatments was similar, but the deep percolation of the former was much higher than that of T7. The reason is that the distribution of irrigation was different during the growth stage. T2 was fully irrigated at the emergence-jointing stage. However, the root system was still underdeveloped during the early stage of growth. Most of the irrigation water was not utilized by plants but directly infiltrated into the deep soil. Therefore, the irrigation at the early growth period can be reduced moderately, and more water should be distributed during the middle and late stages. This irrigation system can effectively reduce deep percolation and increase the utilization of soil storage water.

The simulated actual ET is in good agreement with the observed values. However, the simulated $E_{a}$ is low compared with the study by Yu et al. [21]. The main reasons are as follows: (1) The test was carried out under a shelter, and water can only enter the farmland water circulation system by irrigation at one time. Consequently, the surface soil was dry for a long time. (2) The SWAP model introduces the vegetation cover parameter $V_{c}$ when calculating $\mathrm{E}_{\mathrm{a}}$ and applies it to the correction of soil surface resistance $r_{a}{ }^{s}$ [28]. As a result, the radiation term and aerodynamic term used to calculate $E_{p}$ are reduced. The water requirement of winter wheat in the reproductive growth stage (emergence-heading stage) was obviously higher than that of the vegetative growth stage (heading-maturation stage), and the average ET was $84.96 \mathrm{~mm}$ and $72.77 \mathrm{~mm}$, respectively. This indicated that ensuring adequate water supply in the later growth stages of winter wheat was essential for its healthy growth. The change of ET in different growth stages was closely related to the ratio of $E_{a}$ and $T_{a}$, especially in the early growth period of winter wheat [23]. The plants are young at the emergence-regreening stage, and transpiration is not high. At this stage, the soil evaporation is dominant and does not change obviously. During the wintering stage, the temperature drops and the SWC decreases result in ET gradually declining. The daily ET remains at a low level (less than $2 \mathrm{~mm} \mathrm{~d}^{-1}$ ). The winter wheat grows rapidly during the heading-grouting stage, the root system develops, and the leaf area increases. At the same time, the temperature gradually rises. Therefore, the daily ET increases rapidly. The plants withered at the end of the growth stage, the root activity decreased, leaves wilted, and ET decreased.

Irrigation had a stronger effect on $T_{a}$ than on $E_{a}$. This was because $T_{a}$ was closely related to root water uptake. Different irrigation amounts caused variations in soil water status, and these effects were reflected in the changes in root morphology (root length and density distribution) and physiological functions (root vitality and water uptake) [35,65-67]. Under water stress, roots were vulnerable to drought and died. The decrease in the number of living roots affected the ability of the roots to absorb water, resulting in large differences in $\mathrm{T}_{\mathrm{a}}$. However, in addition to weather parameters such as temperature and radiation, ground cover was the most important factor affecting $E_{a}$ [23]. Comparing the measured data, the LAI had a slight difference among treatments in the same stage. Thus, the $\mathrm{E}_{\mathrm{a}}$ fluctuation was small. The water stress at the emergence-jointing stage had little effect on winter wheat, and ET returned to a normal level after rewetting. Water stress during the heading-grouting stage had a great impact on ET, and ET barely recovered after rewetting. This was because the rapid growth of winter wheat needed to consume a large amount of water at this stage. Water shortage inhibited plant growth, root development and assimilation. This once again emphasizes the importance of irrigation for the later growth stages of winter wheat. Therefore, when designing a deficit irrigation schedule for winter wheat, it can be subjected to a certain degree of water stress before heading. This drought exercise can enhance the drought resistance of winter wheat and improve water use efficiency [4]. However, due to the large water requirement of winter wheat in the later growth stage, it is necessary to provide sufficient irrigation to minimize adverse effects $[20,23]$. 


\section{Conclusions}

This study conducts a sensitivity analysis of the SWAP model through the parameter change method, and concludes that $\theta_{\mathrm{s}}$ and $\mathrm{n}$ are high sensitive parameters that affect the simulation performance of SWC and ET. This clarifies the direction of SWAP model calibration and greatly improves the efficiency of parameter estimation. The method used in this study provides a reference of parameter calibration for crop models without parameter automatic optimization modules. Based on the measured data of the deficit irrigation experiment of winter wheat in Guanzhong Plain, as well as the sensitivity analysis, the SWAP model is calibrated and validated. The calibrated SWAP model has good performance in predicting SWC. The MRE of each treatment is lower than $21.66 \%$, and the RMSE is lower than $0.07 \mathrm{~cm}^{3} \mathrm{~cm}^{-3}$. The simulated ET of winter wheat during the entire growth stage is in good agreement $\left(\mathrm{R}^{2}=0.975, p<0.01\right)$ with the measured values. This makes SWAP a powerful tool to quantitatively analyze the impacts of irrigation on the growth process of winter wheat. The transformation of the farmland water system under different irrigation conditions is analyzed. By investigating the response pattern of winter wheat to different water stress conditions, this study points out the importance of irrigation in the later growth stage of winter wheat, which provides guidance for the formulation of scientific and reasonable irrigation schedules in the actual agricultural production process. Path analysis showed that $\mathrm{CH}$ and SWC of the 0-60 cm layer are strongly correlated with daily ET. The ET calculation model constructed by the above key factors has good performance $\left(\mathrm{R}^{2}=0.727, p<0.01\right)$ and can be used as an effective method to quickly estimate ET under limited parameters.

However, this study paid less attention to the growth process and dry matter accumulation of winter wheat; therefore, further research should be carried out using detailed module of the SWAP model. It is necessary to directly observe the root growth in future studies to improve the simulation accuracy. Finally, the test plots were arranged under a shelter. When precipitation occurred, the air humidity, light and ventilation conditions inside the shelter were slightly different from those outside. The growth of winter wheat was different from that in the larger field. Therefore, additional field trials are needed to enhance the applicability of the research.

Author Contributions: Conceptualization, X.W. (Xiaowen Wang), H.C., L.L. and X.W. (Xiaoyun Wang); methodology, X.W. (Xiaowen Wang), H.C. and L.L.; software, X.W. (Xiaowen Wang), H.C. and L.L.; writing-original draft preparation, X.W. (Xiaowen Wang) and H.C.; writing-review and editing, X.W. (Xiaowen Wang), H.C., L.L. and X.W. (Xiaoyun Wang); visualization, X.W. (Xiaowen Wang); funding acquisition, H.C. All authors have read and agreed to the published version of the manuscript.

Funding: This research was funded by the National Key Research and Development Program of China, grant number 2016YFC0400201 and the National Natural Science Foundation of China, grant number 51879223.

Acknowledgments: We thank Jiatun $\mathrm{Xu}$ and Yunfei Wang for helping us improve the structure of the manuscript.

Conflicts of Interest: The authors declare no conflict of interest.

\section{References}

1. Zheng, Z.; Cai, H.J.; Hoogenboom, G.; Chaves, B.; Yu, L.Y. Limited irrigation for improving water use efficiency of winter wheat in the Guanzhong Plain of Northwest China. Trans. Am. Soc. Agric. Biol. Eng. 2016, 59, 1841-1852.

2. Zhang, X.L.; Xi, L.Y.; Liang, H.Y.; Liu, L.L.; Liao, Y.C.; Liu, Y.; Wen, X.X. Effects of ridge-furrow planting with plastic film mulching and irrigation on grain yield and water use efficiency of winter wheat in Guanzhong Plain. Acta Agric. Boreali-Occident. Sin. 2018, 27, 499-508.

3. Zhang, G.Y.; Zhang, G.Q.; Luo, Q.G.; Ouyang, S.H.; Wei, Y.M. Factors and cluster analysis of quality properties of wheat in Guanzhong Area of Shaanxi Province. J. Triticeae Crop. 2010, 30, 548-554.

4. Sun, H.Y.; Liu, C.M.; Zhang, X.Y.; Shen, Y.J.; Zhang, Y.Q. Effects of irrigation on water balance, yield and WUE of winter wheat in the North China Plain. Agric. Water Manag. 2006, 85, 211-218. [CrossRef]

5. Tang, J.J.; Folmer, H.; Xue, J.H. Technical and allocative efficiency of irrigation water use in the Guanzhong Plain, China. Food Policy 2015, 50, 43-52. [CrossRef] 
6. Zhang, X.Y.; Chen, S.Y.; Sun, H.Y.; Wang, Y.M.; Shao, L.W. Water use efficiency and associated traits in winter wheat cultivars in the North China Plain. Agric. Water Manag. 2010, 97, 1117-1125. [CrossRef]

7. Hussain, M.; Farooq, S.; Jabran, K.; Ijaz, M.; Sattar, A.; Hassan, W. Wheat sown with narrow spacing results in higher yield and water use efficiency under deficit supplemental irrigation at the vegetative and reproductive stage. Agronomy 2016, 6, 22. [CrossRef]

8. Jiang, J.; Huo, Z.L.; Feng, S.Y.; Kang, S.Z.; Wang, F.X.; Zhang, C.B. Effects of deficit irrigation with saline water on spring wheat growth and yield in arid Northwest China. J. Arid Land 2013, 5, 143-154. [CrossRef]

9. Jiang, Y. China's water scarcity. J. Environ. Manag. 2009, 90, 3185-3196. [CrossRef]

10. Piao, S.; Ciais, P.; Huang, Y.; Shen, Z.; Peng, S.; Li, J.; Zhou, L.; Liu, H.; Ma, Y.; Ding, Y.; et al. The impacts of climate change on water resources and agriculture in China. Nature 2010, 467, 43-51. [CrossRef]

11. Zhang, Y.; Han, Q.F.; Cheng, X.F.; Yang, S.S.; Jia, Z.K.; Ding, R.X.; Ren, X.L.; Nie, J.F. Effects of ridge and furrow rain harvesting with supplemental irrigation on winter wheat photosynthetic characteristics, yield and water use efficiency in Guanzhong irrigation district. Chin. J. Appl. Ecol. 2015, 26, 1382-1390.

12. Tang, J.J.; Folmer, H.; Xue, J.H. Adoption of farm-based irrigation water-saving techniques in the Guanzhong Plain, China. Agric. Econ. 2016, 47, 445-455. [CrossRef]

13. Wang, J.X.; Huang, J.K.; Zhang, L.J.; Huang, Q.Q. Do incentives still matter for the reform of irrigation management in the Yellow River Basin in China? J. Hydrol. 2014, 517, 584-594. [CrossRef]

14. Ali, M.H.; Hoque, M.R.; Hassan, A.A.; Khair, A. Effects of deficit irrigation on yield, water productivity, and economic returns of wheat. Agric. Water Manag. 2007, 92, 151-161. [CrossRef]

15. Ishaque, W.; Abbas, F.; Ali, S.; Mahmood, K.; Zaman, Q.; Azam, M.; Khan, I.; Zain, M. Yield response of wheat (Triticum aestivum L.) to deficit and regulated deficit irrigation under aridsemi-arid conditions. Pak. J. Agric. Sci. 2017, 54, 135-144.

16. Sarwar, A.; Bastiaanssen, W.G.M.; Feddes, R.A. Irrigation water distribution and long-term effects on crop and environment. Agric. Water Manag. 2001, 50, 125-140. [CrossRef]

17. Tejero, I.G.; Zuazo, V.H.D.; Bocanegra, J.A.J.; Fernández, J.L.M. Improved water-use efficiency by deficit-irrigation programmes: Implications for saving water in citrus orchards. Sci. Hortic. 2011, 128, $274-282$. [CrossRef]

18. Xia, G.J.; Yan, Y.L.; Cheng, S.M.; Gao, S.J.; Luo, Y. Research on compensatory effects to water deficits on dryland winter wheat. Agric. Res. Arid Areas 2001, 19, 79-82.

19. Zhao, L.Y.; Deng, X.P.; Lun, S. A review on types and mechanisms of compensation effect of crops under water deficit. Chin. J. Appl. Ecol. 2004, 15, 523-526.

20. Tari, A.F. The effects of different deficit irrigation strategies on yield, quality, and water-use efficiencies of wheat under semi-arid conditions. Agric. Water Manag. 2016, 167, 1-10. [CrossRef]

21. Yu, L.Y.; Zeng, Y.J.; Su, Z.B.; Cai, H.J.; Zheng, Z. The effect of different evapotranspiration methods on portraying soil water dynamics and ET partitioning in a semi-arid environment in Northwest China. Hydrol. Earth Syst. Sci. 2016, 20, 975-990. [CrossRef]

22. Schneider, A.D.; Howell, T.A. Scheduling deficit wheat irrigation with data from an evapotranspiration network. Trans. Am. Soc. Agric. Eng. 2001, 44, 1617-1623. [CrossRef]

23. Wang, Z.S.; Cai, H.J.; Yu, L.Y.; Wang, X.W.; Shi, X.H. Estimation of evapotranspiration and soil evaporation of winter wheat in arid region of Northwest China based on SIMDual Kc model. Trans. Chin. Soc. Agric. Eng. 2016, 32, 126-136.

24. Anderson, R.; French, A. Crop evapotranspiration. Agron. Basel 2019, 9, 614. [CrossRef]

25. Chia, M.Y.; Huang, Y.F.; Koo, C.H.; Fung, K.F. Recent advances in evapotranspiration estimation using artificial intelligence approaches with a focus on hybridization techniques-A Review. Agron. Basel 2020, 10, 101. [CrossRef]

26. Neukam, D.; Ahrends, H.; Luig, A.; Manderscheid, R.; Kage, H. Integrating wheat canopy temperatures in crop system models. Agronomy 2016, 6, 7. [CrossRef]

27. Leghari, S.J.; Hu, K.L.; Liang, H.; Wei, Y.C. Modeling water and nitrogen balance of different cropping systems in the North China Plain. Agronomy 2019, 9, 696. [CrossRef]

28. Kroes, J.G.; van Dam, J.C.; Bartholomeus, R.P.; Groenendijk, P.; Heinen, M.; Hendriks, R.F.A.; Mulder, H.M.; Supit, I.; van Walsum, P.E.V. SWAP Version 4: Theory Description and User Manual; Wageningen Environmental Research: Wageningen, The Netherlands, 2017. 
29. Eitzinger, J.; Trnka, M.; Hösch, J.; Žalud, Z.; Dubrovský, M. Comparison of CERES, WOFOST and SWAP models in simulating soil water content during growing season under different soil conditions. Ecol. Model. 2004, 171, 223-246. [CrossRef]

30. Bonfante, A.; Basile, A.; Acutis, M.; De Mascellis, R.; Manna, P.; Perego, A.; Terribile, F. SWAP, CropSyst and MACRO comparison in two contrasting soils cropped with maize in Northern Italy. Agric. Water Manag. 2010, 97, 1051-1062. [CrossRef]

31. Ma, Y.; Feng, S.Y.; Huo, Z.L.; Song, X.F. Application of the SWAP model to simulate the field water cycle under deficit irrigation in Beijing, China. Math. Comput. Model. 2011, 54, 1044-1052. [CrossRef]

32. Confalonieri, R.; Bellocchi, G.; Tarantola, S.; Acutis, M.; Donatelli, M.; Genovese, G. Sensitivity analysis of the rice model WARM in Europe: Exploring the effects of different locations, climates and methods of analysis on model sensitivity to crop parameters. Environ. Model. Softw. 2010, 25, 479-488. [CrossRef]

33. Zeng, W.Z.; Lei, G.Q.; Zha, Y.Y.; Fang, Y.H.; Wu, J.W.; Huang, J.S. Sensitivity and uncertainty analysis of the HYDRUS-1D model for root water uptake in saline soils. Crop. Pasture Sci. 2018, 69, 163-173. [CrossRef]

34. Song, L.B.; Chen, S.; Yao, N.; Feng, H.; Zhang, T.B.; He, J.Q. Parameter estimation and verification of CERES-maize model with GLUE and PEST methods. Trans. Chin. Soc. Agric. Mach. 2015, 46, 95-111.

35. Wang, X.W.; Cai, H.J.; Zheng, Z.; Yu, L.Y.; Wang, Z.S.; Li, L. Modelling root water uptake under deficit irrigation and rewetting in Northwest China. Agron. J. 2020, 112, 158-174. [CrossRef]

36. Richards, L.A. Capillary conduction of liquids through porous mediums. Physics 1931, 1, 318-333. [CrossRef]

37. Feng, S.Y.; Jiang, J.; Huo, Z.L.; Zhang, C.B. Optimization of irrigation scheduling under deficit irrigation with saline water for spring wheat based on SWAP model. Trans. Chin. Soc. Agric. Eng. 2014, 30, 66-75.

38. Hassanli, M.; Ebrahimian, H.; Mohammadi, E.; Rahimi, A.; Shokouhi, A. Simulating maize yields when irrigating with saline water, using the AquaCrop, SALTMED, and SWAP models. Agric. Water Manag. 2016, 176, 91-99. [CrossRef]

39. Feddes, R.A.; Kowalik, P.J.; Zaradny, H. Simulation of Field Water Use and Crop Yield; Centre for Agricultural Publishing and Documentation: Wageningen, The Netherlands, 1978.

40. Cai, G.C.; Vanderborght, J.; Langensiepen, M.; Schnepf, A.; Hüging, H.; Vereecken, H. Root growth, water uptake, and sap flow of winter wheat in response to different soil water conditions. Hydrol. Earth Syst. Sci. 2018, 22, 2449-2470. [CrossRef]

41. Yang, D.J.; Zhang, T.Q.; Zhang, K.F.; Greenwood, D.J.; Hammond, J.P.; White, P.J. An easily implemented agro-hydrological procedure with dynamic root simulation for water transfer in the crop-soil system: Validation and application. J. Hydrol. 2009, 370, 177-190. [CrossRef]

42. Jha, S.K.; Gao, Y.; Liu, H.; Huang, Z.D.; Wang, G.S.; Liang, Y.P.; Duan, A.W. Root development and water uptake in winter wheat under different irrigation methods and scheduling for North China. Agric. Water Manag. 2017, 182, 139-150. [CrossRef]

43. Guo, J.M. Simulation of Regional Winter Wheat Growth by Using Remote Sensing Data and Crop Growth Model; Nanjing University of Information Science \& Technology: Nanjing, China, 2007.

44. Hamby, D.M. A review of techniques for parameter sensitivity analysis of environmental models. Environ. Monit. Assess. 1994, 32, 135-154. [CrossRef] [PubMed]

45. Sun, Y. The Numerical Inversion of Soil Hydraulic Parameters Based on PEST; China University of Geosciences: Beijing, China, 2017.

46. Xu, S.N. Simulation of Winter Wheat in Jiangsu Province with the Modified WOFOST Model Based on Remote Sensing Data; Nanjing University of Information Science \& Technology: Nanjing, China, 2016.

47. van Genuchten, M.T.; Leij, F.J.; Yates, S.R.; Williams, J.R. The RETC Code for Quantifying the Hydraulic Functions of Unsaturated Soils; U.S. Department of Agriculture, Agricultural Research Service, U.S. Salinity Laboratory: Riverside, CA, USA, 1991.

48. Li, S.; Zhao, X.J.; Xie, Y.; Zhai, J.R.; Liu, G.; Gao, X.F.; Li, J.; Gao, Y. Parameter estimation of soil water retention curve based on soil physical and chemical properties of Van Genuchten model. Sci. Geogr. Sin. 2018, 38, 1189-1197.

49. Gao, H.B.; Shao, M.A. Effect of temperature on soil moisture parameters. Adv. Water Sci. 2011, 22, 484-494.

50. Yao, Y.F.; Shao, M.A. Effect of measure time on soil saturated hydraulic conductivity by constant head method. Chin. J. Soil Sci. 2015, 46, 327-333.

51. Helton, J.C.; Davis, F.J.; Johnson, J.D. A comparison of uncertainty and sensitivity analysis results obtained with random and Latin hypercube sampling. Reliab. Eng. Syst. Saf. 2005, 89, 305-330. [CrossRef] 
52. Iman, R.; Conover, W.J. A measure of Top-Down correlation. Technometrics 1987, 29, 351-357.

53. Savage, I.R. Contributions to the theory of rank order statistics-the two-sample case. Ann. Math. Stat. 1956, 27, 590-615. [CrossRef]

54. Tan, J.W. Study on Parameter Sensitivity and Model Uncertainty Analysis of Crop Model; Wuhan University: Wuhan, China, 2017.

55. Guo, X.H.; Sun, X.H.; Ma, J.J.; Lei, T.; Zheng, L.J.; Wang, P. Simulation of the water dynamics and root water uptake of winter wheat in irrigation at different soil depths. Water 2018, 10, 1033-1049. [CrossRef]

56. Wright, S. Systems of mating. i. the biometric relations between parent and offspring. Genetics 1921, 6, 111-123.

57. Astereki, H.; Sharifi, P.; Pouresmael, M. Correlation and path analysis for grain yield and yield components in chickpea (Cicer arietinum L.). Genetika 2017, 49, 273-284. [CrossRef]

58. de Almeida Rios, S.; Vieira da Cunha, R.N.; Lopes, R.; Barcelos, E.; Raimundo Nonato Carvalho da, R.; Alves de Lima, W.A. Correlation and path analysis for yield components in dura oil palm germplasm. Ind. Crop. Prod. 2018, 112, 724-733. [CrossRef]

59. Hladni, N.; Jocic, S.; Mijic, A.; Miklic, V.; Miladinovic, D. Correlation and path analysis of yield and yield components of confectionary sunflower. Genetika 2016, 48, 827-835. [CrossRef]

60. Seker, H.; Serin, Y. Explanation of the relationships between seed yield and some morphological traits in smooth bromegrass (Bromus inermis Leyss.) by path analysis. Eur. J. Agron. 2004, 21, 1-6. [CrossRef]

61. Singh, U.K.; Ren, L.; Kang, S. Simulation of soil water in space and time using an agro-hydrological model and remote sensing techniques. Agric. Water Manag. 2010, 97, 1210-1220. [CrossRef]

62. Zhang, X.Y.; Pei, D.; Chen, S.Y. Root growth and soil water utilization of winter wheat in the North China Plain. Hydrol. Process. 2004, 18, 2275-2287. [CrossRef]

63. Engels, C.; Mollenkopf, M.; Marschner, H. Effect of drying and rewetting the topsoil on root-growth of maize and rape in different soil depths. Z. Pflanz. Bodenkd. 1994, 157, 139-144. [CrossRef]

64. Xu, X.; Bland, W.L. Resumption of water uptake by sorghum after water stress. Agron. J. 1993, 85, 697-702. [CrossRef]

65. Feddes, R.A.; Hoff, H.; Bruen, M.; Dawson, T.; de Rosnay, P.; Dirmeyer, P.; Jackson, R.B.; Kabat, P.; Kleidon, A.; Lilly, A.; et al. Modeling root water uptake in hydrological and climate models. Bull. Am. Meteorol. Soc. 2001, 82, 2797-2809. [CrossRef]

66. Feddes, R.A.; Kowalik, P.; Kolinska-Malinka, K.; Zaradny, H. Simulation of field water uptake by plants using a soil water dependent root extraction function. J. Hydrol. 1976, 31, 13-26. [CrossRef]

67. Li, C.X.; Zhou, X.G.; Sun, J.S.; Wang, H.Z.; Gao, Y. Dynamics of root water uptake and water use efficiency under alternate partial root-zone irrigation. Desalin. Water Treat. 2013, 52, 2805-2810. [CrossRef]

Publisher's Note: MDPI stays neutral with regard to jurisdictional claims in published maps and institutional affiliations.

(C) 2020 by the authors. Licensee MDPI, Basel, Switzerland. This article is an open access article distributed under the terms and conditions of the Creative Commons Attribution (CC BY) license (http://creativecommons.org/licenses/by/4.0/). 